OPEN ACCESS

Edited by:

Efi Paparistodemou,

Cyprus Pedagogical Institute, Cyprus

Reviewed by:

Janna Kellinger,

University of Massachusetts Boston,

United States

Nancy Longnecker,

University of Otago, New Zealand

*Correspondence:

Fredrik Breien

fredrik.breien@uib.no

Specialty section:

This article was submitted to

Digital Learning Innovations,

a section of the journal

Frontiers in Education

Received: 14 September 2021 Accepted: 08 December 2021

Published: 14 January 2022

Citation:

Breien F and Wasson B (2022) eLuna: A Co-Design Framework for Narrative

Digital Game-Based Learning that Support STEAM.

Front. Educ. 6:775746.

doi: $10.3389 /$ feduc.2021.775746

\section{eLuna: A Co-Design Framework for Narrative Digital Game-Based Learning that Support STEAM}

\author{
Fredrik Breien $^{1,2,3 *}$ and Barbara Wasson ${ }^{1,2,3}$ \\ ${ }^{1}$ University of Bergen, Bergen, Norway, ${ }^{2}$ Department of Information and Media Studies, Faculty of Social Sciences, University of \\ Bergen, Bergen, Norway, ${ }^{3}$ Center for the Science of Learning \& Technology, Faculty of Psychology, University of Bergen, Bergen, \\ Norway
}

STEAM education enables the cross-curricular study of subjects based on their naturally occurring relationships through holistic and integrated methods. Narratives are enablers of STEAM learning environments, something that is evident in the exploration of narrative learning from pre-recorded history until present. Narrative Digital Game-Based Learning (DGBL) use narratives to drive the game. The extended Ludo Narrative Variable Model (the Variable Model) is a narratological model for categorization of narrative DGBL. Empirical evidence from categorizing narrative DGBL on the Variable Model shows that there is a particular set of categories that incur positive effects on engagement, motivation, and learning. This article introduces the eLuna co-design framework that builds on these categories and empowers educators to participate alongside game developers in multidisciplinary design and development of narrative DGBL. eLuna comprises 1) a four-phase co-design method, and 2) a visual language to support the co-design and co-specification of the game to a blueprint that can be implement by game developers. Idun's Apples, a narrative DGBL co-designed, co-specified, and implemented into a prototype using eLuna, is presented to illustrate the use of the method and visual language. Arguing that narrative DGBL are vessels for STEAM learning, seven eLuna co-designed games are examined to illustrate that they support STEAM. The article concludes that narrative DGBL co-designed using the eLuna framework provide high opportunity and potential for supporting STEAM, providing educators and game developers with a STEAM co-design framework that enforces positive effects on engagement, motivation, and learning.

\section{Keywords: narratives, games, digital game-based learning, co-design framework, co-design, technology enhance learning (TEL)}

\section{INTRODUCTION}

Teaching and learning in STEAM allows for cross-curricular study of subjects based on their naturally occurring relationships through holistic and integrated methods. STEAM integrates Arts with STEM (Science, Technology, Engineering, and Mathematics). Yakman (2008) defines the classification of STEAM subjects as:

- Science: What exists naturally and how it is affected

- Technology: What is human made 
- Engineering: The use of creativity and logic, based in mathematics and science, utilizing technology as a linking agent to create contributions to the world

- Arts: How society develops, impacts, is communicated and understood with its attitudes and customs in the past, present and future

- Mathematics: Numbers and operations, algebra, geometry, measurement, data analysis and probability, problem solving, reasoning and proof, communication, trigonometry, and calculus,

Research has shown that games and narrative learning environments have the potential to address Arts and embed it within study of STEM subjects. An example is illustrated by Pant et al. (2020), showing that adding stories and poems to mathematical education creates increased motivation and meaningful engagement towards mathematical classroom education. Another example is provided by Hunter-Doniger et al. (2018) who, realizing that non-arts educators need to learn how to infuse the culturally relevant arts into STEM, created a unique approach to STEAM through storytelling. The approach 1) emboldened children in constructing academic knowledge, 2) gave students the voice or the cultural competence to approach standards in ways that make the information relevant, and 3) gave students the opportunity to develop a socio-political consciousness and evoke change. A third example is found in Bronwyn et al. (2021), who showed that participation in story-worlds lays foundation for STEAM education that led to new understanding in neuroscience, sustainability, physics, and space science.

The research presented in this article enforces this position by first exploring narrative learning traditions in a historic perspective, before placing an emphasis on narratives in digital game-based learning (DGBL) and showing how DGBL, too, are narratives that enable cross-curricular learning environments for STEAM subjects. Having established that narrative (digital) gamed-based learning supports STEAM, the eLuna framework, a multidisciplinary co-design framework for developing narrative DGBL, is presented and its use illustrated through a description of the co-design of a narrative DGBL named Idun's Apples. Then, seven narrative DGBL that were co-designed using the eLuna framework (including Idun's Apples) are investigated for their support of STEAM education. The findings and discussion argue that eLuna is usable as a multidisciplinary co-design and specification framework for creating effective narrative DGBL that supports STEAM education.

\section{BACKGROUND}

This section explores narratives and their application for STEAM from a historical perspective, before presenting narrative digital game-based learning (DGBL) and showing how these can be considered STEAM learning environments. Then, perspectives on, and requirements for, co-design frameworks for both STEAM and DGBL are presented.

\section{A Historical Perspective on Narrative Learning and STEAM}

Narratives use to support learning dates to prehistoric times. People started formulating narratives alongside developing speech, and these emergent narratives soon included units of information enabling humans to learn about themselves and the worlds in which they lived (Zipes, 2012). In prehistoric times, informative tales were told to "mark an occasion, set an example, warn about danger, procure food, or explain what seemed inexplicable. People told stories to communicate knowledge and experience in social contexts" (Zipes, 2012, p. 2). In the STEAM perspective, for example, the transfer of the 'knowledge' about 'procuring food' (as the 15,000 year old Lascaux cave paintings have been speculated to be used for (Curtis, 2008), may include STEM through methods for hunting and growing (Science), equipment to use, such as spears or traps for hunting, or systems of irrigation and tools for harvesting (Technology), how to plan and build equipment or installations (Engineering), and the laws of physics based constraints in play while developing methods and functional equipment, such as integrity of material to use, depths, diameters, and other measures such as fortifications of installations used for trapping, herding, or storing (Mathematics). Regardless of whether such prehistoric narratives emphasised one or the other of these core STEM subjects, they certainly integrated holistically across curriculums through naturally occurring relationships. These STEM subjects further integrate meaningful Arts subjects by communicating knowledge and experience in social contexts. For example, the reasons for, and cultural parameters related to, food procurement provide meaning in the time and place for learning, as would exploring the efforts needed to sustain a society, population development, demographics, climatic and environmental conditions, social goals and norms, laws and rules, culturally dependent ethics and belief systems, political situations. In short, STEAM education encompasses learning, as formulated by Yakman (2008 p.16), how society develops, impacts, is communicated and understood, with its attitudes and customs in the past, present, and future. Equally, in a modern perspective more recent philosophical texts apply narratives in inherently STEAM learning environments. This can be seen, for example, in the classic work The Tragedy of the Commons (Hardin, 1968), which places an emphasis on the Arts in social sciences, ethics, law, and sustainability, but which also includes natural occurring cross-curricular relationships to biology (Science), construction, manufacturing, and design (Technology), agriculture (Engineering), and numerical operations, measurements, data analysis, reasoning, and problems solving (Mathematics).

\section{Narrative Digital Game-Based Learning}

In current research, Digital Game-Based Learning (DGBL) (Prensky, 2001) is regarded to constitute three major variations: 1) Serious Games, full featured video games created with the purpose to teach someone something, 2) Gamification, using a subsets of video game features, and integrating them in non-game learning systems to in some way or another enhance the learning situation, effect, or outcome, and, 3) Commercial off 
the Shelf (COTS) games used as an integrated part of any form of non-game-based learning and training process (Breien and Wasson, 2021). The Logo educational video game, designed by Feurzeig, Papert, and Solomon in $1967^{1}$, and described 7 years later by Abelson, Goodman, and Rudolph (1974) can, according to Jeremy Chen of Immersed Games, be considered the first educational video game, as it "blended mathematics and programming by allowing teaching players the basics of coding by directing a turtle-shaped cursor to draw lines" Soon after, and more famous than Logo, came Oregon Trail, a 1971 educational video game published by Minnesota Educational Computing Consortium (MECC) ${ }^{3}$. Oregon Trail was soon assimilated in schools, where the game, through several version lifecycles, remained in use for 30 years ${ }^{4}$. Primarily, Oregon Trail was used in history education for teaching 8th graders in the United States the realities of 19thcentury pioneer life through the DGBLs narrative. The game included naturally occurring relationships to STEM subjects in that the game players also needed to 1) balance finances to acquire supplies, 2) manage resources in inventories based on weight and load capacities, 3) procure food and equipment along the way through hunting and trading, and 4) calculate travel speed dependent on load weights, natural topographical, and weather conditions. In their summary of the origin of serious games, Djaouti, Alvarez, Jessel, and Rampnoux (2011) attribute Oregon Trail as being "One of the most famous ancestors of current serious games" (p. 8), a game that shows us how "an educational or serious game is not necessarily the opposite to a popular and commercially successful game" (p. 9).

The trend of narrative DGBL that support cross-curricular learning of naturally occurring relationships in STEAM subjects continues in modern times. An example is found in the Crystal Island DGBL (Rowe et al., 2010; Rowe et al., 2011; Lester, et al., 2014). Crystal Island exists in two versions in a shared setting based on the Arts, in which a social structure constituting the members of a science team with formal roles and responsibilities are isolated on a deserted island and victims to an unknown epidemic. Additionally, one of the Crystal Island versions focuses on microbiology and medicine (Science), and the other on cartographical tools (Technology). Through both versions, Crystal Island emphasises construction (Engineering), and measures, reasoning, and problem solving (Mathematics) as supporting STEAM disciplines. The objective of Crystal Island is to stop the epidemic and diagnose the cause through effective medical research and containment measures, and to escape the island quickly through detailed mapping, orientation, and subsequent effective emergency signalling. Another example is the Cache 17 DGBL (described in Pilegard and Mayer, 2016), which teaches wet-cell battery construction (Engineering) and functionality (Technology), with cross-curricular naturally

${ }^{1}$ https://en.wikipedia.org/wiki/Logo_(programming_language).

${ }^{2} \mathrm{http}: / /$ www.immersedgames.com/the-history-of-educational-video-gaming.

${ }^{3}$ https://en.wikipedia.org/wiki/The_Oregon_Trail_(series).

${ }^{4}$ https://www.smithsonianmag.com/innovation/how-you-wound-playing-emoregon-trailem-computer-class-180959851/. occurring relationships to chemistry (Science), measurement, probability, and problem solving (Mathematics), using a history, law, and economic (Art) setting, in which two insurance agents penetrate an old war bunker to obtain pieces of stolen art.

\section{Empowering Co-Designers in STEAM and Narrative Digital Game-Based Learning}

Narrative DGBL is a media with high potential to enrich STEAM environments in education. STEAM environments allow for holistic and integrated cross-curricular study of subjects based on their naturally occurring relationship with one another requiring multidiscipline educators involved in the development of learning materials. As Hunter-Doniger et al. (2017) have pointed out, STEM educators need methods to integrate culturally relevant arts in education to properly deliver STEAM structures in education. Observing difficulties to transdisciplinary teaching, arts integration, and collaborative learning, Milara et al. (2020) initiated STEAM educator training across subjects to increasing teachers' collaborative awareness, thus scaffolding Communities of Practice for educators' development of STEAM digital fabrication. Pointing to calls for interdisciplinary approaches to education nurturing stronger synergies between STEAM subjects, Finch et al. (2018) use storyline authoring (Reiser et al., 2013) as a workshop-based co-design framework bringing together educators from arts, science, and computing disciplines, blending their expertise to counter stagnant and marginalizing practices in those disciplines. Seeing how STEAM subjects need recognition, embracement, and prioritisation of different forms of disciplinary knowledge that can be identified in the spaces between disciplinary curriculum and pedagogy, MacDonald et al. (2019) compel educators to dissolve and transcend disciplinary boundaries through the enactment of emergent interdisciplinary pedagogies that generate interdisciplinary learning. As these examples show, the need for empowering co-design frameworks and methods are apparent in STEAM learning environment development.

Similarly, the design and development of narrative DGBL requires a multidisciplinary team and an approach that enables and empowers educators and game designers in their co-design of narrative DGBL. As pointed out by Silva (2020), to create a DGBL that is both educationally efficient and fun to play, both game experts and educational experts must be able to communicate efficiently in the design process. Focusing on the role of educators, but implying the need for game designers, Marchiori et al. (2011) emphasises the need to empower educators with no technical background so that they can participate in DGBL design and development. Arnab et al. (2015) point to the lack of tools that allow educators to understand how to implement serious games in education, an observation which is shared by Lameras et al. (2017) who stress the need for pedagogically driven, inclusive processes of serious game design. Focusing on the game designer role, Carvalho et al. (2015) points to a gap between idea and implementation, due to a lack of models, methods, and frameworks to help understand how DGBL requirements are 


\section{eLuna Framework}

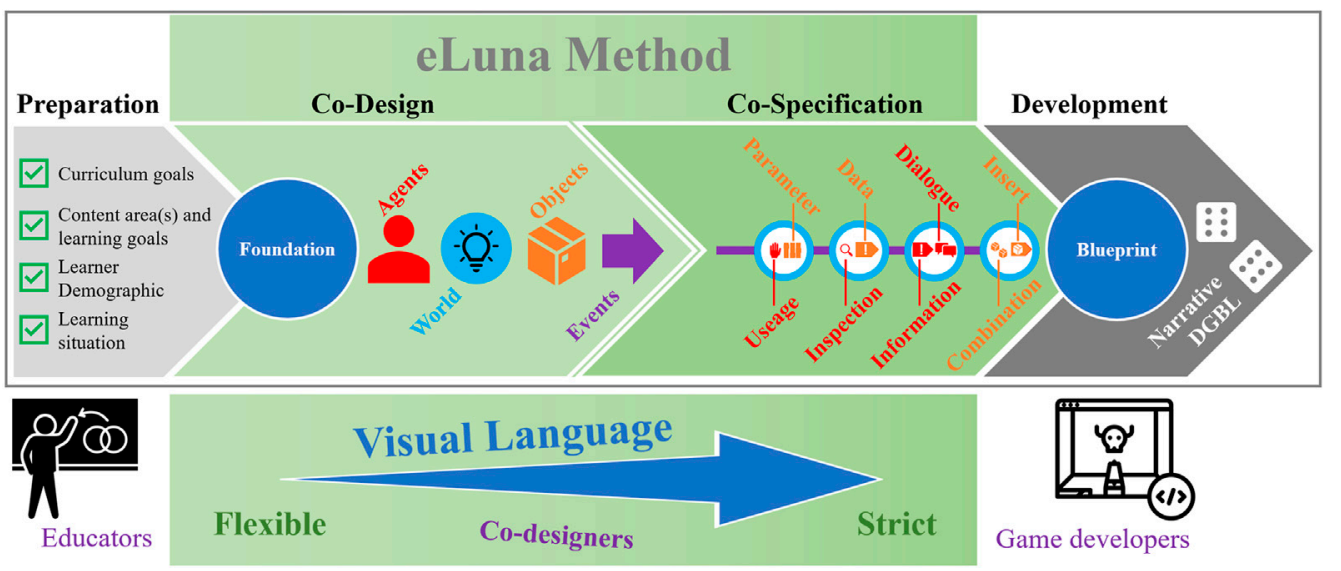

FIGURE 1 | The eLuna framework.

to be concretely satisfied. All in their own way, and combined, this research amplifies the notion that to make effective DGBL that help learners reach their learning goals, educators and game developers needs to be equally empowered in their co-design.

Narrative DGBL is most effective in reaching learning goals when the narratives are designed as non-linear (Breien and Gkini, 2021). Performing a structured search ${ }^{5}$ for scientific articles about DGBL design frameworks across five academic databases ${ }^{6}$ and in the five highest ranked e-learning journals by impact factor ${ }^{7}$ resulted in 67 articles, 17 of which presented frameworks for DGBL. Of these, $17^{8}$ none mention STEAM or STEM. While 12 of the 17 mention narratives or stories, only six articles name narratives as components of the DGBL. Three present a component that exists separately from, and alongside, the game experience (Westera, et al., 2008; Carvalho, et al., 2015; Lameras et al., 2017), and three as a game component equal to any other component in the game, such as the world, the interactions, and the art (Marchiori, et al., 2011; Arnab, et al., 2015; Silva, 2020). According to a narrative theory of games (Aarseth, 2012), this implies borrowing and adapting classical models for narrative design from other dominant media (such as books, films, or theatrical plays). Borrowing models from other media does not lend itself to fully taking advantage of the non-linear narrative

${ }^{5}$ Using the search string < Design AND (Method ${ }^{*}$ OR Process OR Framework) AND ("Serious Game” OR "Serious Games" OR "Digital Game Based Learning")> with no date/year restriction.

${ }^{6}$ ACM Digital Library, IEEE Explore, PsycINFO, Science Direct, and Web of Science.

${ }^{7}$ As per Scimago Journal and Country Rank, end of year 2019: Internet and Higher Education, Computers and Education, Government Information Quarterly, British Journal of Educational Technology, and Journal of Computer Assisted Learning. ${ }^{8}$ From 67 before a) duplicate removal (8), b) false positive removal (27), and c) excluding articles that concerned the same frameworks, as well as articles that described having used a framework but do not include details about how it worked (15). structures available through games, since classical models are not able to fully classify non-linear narratives (Breien and Gkini, 2021). According to a narrative theory of games (Aarseth, 2012), games should be considered as a dominant narrative media employing its own models for proper analysis and design. Thus, we identify a need for the development of frameworks for co-design of narrative DGBL that adheres to the narrative theory of games and the categories available through non-linear narratives that are associated with positive learning effects.

\section{THE ELUNA FRAMEWORK}

The eLuna framework (see Figure 1) supports educators and game developers (co-designers) to methodologically co-design narrative digital game-based learning (DGBL). Beginning with educators defining curricular content, learning objectives content area, learner demographics, and the learning situation in a preparatory phase, eLuna guides co-designers through codesign that produces a game description in table format, and a co-specification phase that results in a narrative DGBL blueprint. In a final development phase, the blueprint is used as basis for development of a narrative DGBL. Through the co-design and cospecification phases, eLuna employs a visual language based on icons, colours, and written descriptions that enables a methodological process that is used partially and flexibly through the design phase, allowing participants to focus on overarching game principles and elements, and fully and strictly through the specification phase, that results in an unambiguous technical blueprint that forms the basis for development of the narrative DGBL.

A DGBL can be categorized according to how it meets elements of a game and a narrative that is defined by ontologies that includes a world, objects, agents, and events, described more fully in Section 3.2. These are mapped against scales from narrative to game mechanical. A DGBL's ontological 
TABLE 1 | The extended Ludo Narrative Variable Model, highlighting the categories associated with positive effects on engagement, motivation, and learning (Breien and Wasson, 2021)

\begin{tabular}{|c|c|c|c|c|}
\hline Ontology polarity & World & Objects & Agents & Events \\
\hline Narrative pole & Inaccessible & Non-interactable & Deep, rich, round & Fully plotted \\
\hline \multirow[t]{3}{*}{ High author agency } & Single room & Static, usable & Grounded, consistent & $\mathrm{N} / \mathrm{A}$ \\
\hline & Linear corridor & Modifiable & Sensible & Linear fixed kernels, dynamic satellites \\
\hline & Multicursal labyrinth & Destructible & Flat & Interchangeable fixed kernels, dynamic or fixed satellites \\
\hline High game agency & Hub shaped quest landscape & Creatable & Stereotypical & Dynamic kernels \\
\hline Ludic (game) pole & Open landscape & Inventible & Bots, no individual identity & No kernels (pure game) \\
\hline
\end{tabular}

categorization defines its author and game agency from a narrative pole to a ludic (game pole), each at the cost of expressive freedom of the other; a game high author agency under an ontology allows for narrative expressive freedom, at the sacrifice of game mechanical flexibility, and vice-versa. Consider two examples, a classical narrative and a classical game: The Old Man and the Sea (Hemingway, 1995), and Chess. The former employs high author agency to tell a story about an old man that sustains himself by fishing, and that goes on an existential journey at sea. Providing high mechanical flexibility, adding high game agency to The Old Man and the Sea, could for example imply allowing the observer of the story, the player, to decide that the old man goes somewhere else that day, not heading out to sea at all, which would greatly inhibit the author's (Hemingway's) agency to tell the details of his intended story. Similarly, in chess, accommodating for high author agency by for example dictating the white player to move a certain playing piece in a certain way when making the opening move, because that particular match is to tell a story about how that piece started it all, would sacrifice the mechanical flexibility of the entire match, rendering any opening strategy, a vital part of chess, obsolete.

The eLuna framework targets narrative DGBL categories identified in the extended Ludo Narrative Variable Model (the Variable Model) that have been shown to incur positive effects on engagement, motivation, and learning, termed fully positive effects (Breien and Wasson, 2021). The Variable Model categories, see Table 1, are sorted by ontologies World, Objects, Agents, and Events and the highlighted categories are those that are associated with fully positive effects.

As can be seen in Table 1, the Variable Model categories exist on polar scales from high author agency, where the design of deep narratives is at the cost of game mechanical flexibility, to high game agency, which allows the design of flexible game mechanics at the cost of narrative depth. The fully positive effects categories, Hubshaped Quest Landscape Worlds, Modifiable Objects, Grounded and Consistent Agents, and Interchangeable Fixed Kernel Events are described by what characterizes them, which is as follows:

- Hubshaped Quest Landscape: A World (landscape) consisting of confined areas (hubs) that are explored at will, and in which completing tasks in sequences (quests) open new hubs in the landscape, depending on player choices.
- Modifiable Objects: Objects in the World that may be altered, combined, or configured to overcome challenges and reach objectives through completing tasks.

- Grounded and Consistent Agents: Characters in the game narrative with sensible and well described backgrounds, psychologies, and goals.

- Interchangeable Fixed Kernels: Storyline events of high importance that are pre-written and interchangeable among each other, allowing for traversing a story in different orders based on player choices

As seen from the characteristics, a narrative DGBL associated with fully positive effects is a system in which the player/learner guide describes characters using complex objects to perform tasks in select and non-deterministic sequences in an expanding world where pre-written chapters of a story are experienced in optional sequences. The eLuna framework targets the categories that are associated with fully positive effects. The next sections present the eLuna method and visual language.

\section{The eLuna Method}

The eLuna method has been iteratively developed through three co-design workshops in which 2 teams of co-designers (20 in all), all with background from education (10 teachers from high school to university college levels), educational technologies (six experts holding PhDs in Technology Enhanced Learning related areas), or DGBL development (four developers from the serious games industry) followed the method. Each workshop was facilitated and moderated by a researcher, was evaluated by the co-designers, and the method was updated before the next workshop. Thus, the three workshops resulted in six narrative DGBL co-designs. Table 2 presents the 4 phases of the eLuna method.

Educators work alone during the Preparatory phase to identify the curriculum goals, the content area and/or learning objectives, the learner demographic, and the learning situation. Educators and Game developers work together in the Co-Design phase supported by a simplified version of the visual language (see Section 3.2). Using the preparatory material as guidance they exploratorily uncover all the elements of the narrative DGBL (in the order of agents, world, objects and events) and show how they work together while conforming to the characteristics of the targeted Variable Model categories; this is presented in a quest and task design. At this stage there is no obligation to tie the entire game flow together in a technical and unambiguous manner. During the third phase, Co-Specification, co-designers use the 
TABLE 2 | The eLuna method.

\begin{tabular}{|c|c|c|c|}
\hline & Phase & Activity & Participants \\
\hline & 1 Preparation & 1.1 Summarize curriculum goal(s) & Educators \\
\hline & & 1.2 Define content area(s) and learning goals & Educators \\
\hline & & 1.3 Describe learner demographic & Educators \\
\hline & & 1.4 Describe learning situation & Educators \\
\hline \multirow[t]{5}{*}{ Simplified and flexible visual language } & 2 Co-design & 2.1 Present preparatory work & Educators and Game Developers \\
\hline & & 2.2 Design the Agents & Educators and Game Developers \\
\hline & & 2.3 Design the World & Educators and Game Developers \\
\hline & & 2.4 Design the Objects & Educators and Game Developers \\
\hline & & 2.5 Design the Events & Educators and Game Developers \\
\hline \multirow[t]{6}{*}{ Complete and strict visual language } & 3 Co-Specification & 3.1 Specifying the hubs and quests & Educators and Game Developers \\
\hline & & 3.2 Specifying Agents and Objects in quests & Educators and Game Developers \\
\hline & & 3.3 Specifying Agents dialogues & Educators and Game Developers \\
\hline & & 3.4 Specifying Events narrative passages & Educators and Game Developers \\
\hline & 4 Development & 4.1 Developing the narrative DGBL & Game developers \\
\hline & & 4.2 Deploying the narrative $\mathrm{DGBL}$ & Game developers \\
\hline
\end{tabular}

complete visual language (see Section 3.2) adhering to its strict rules to translate the Quest and Task design into a Blueprint for the game. The blueprint unambiguously describes the game flow in a technical manner sufficient enough to serve as a basis for a narrative DGBL that can be developed. In the fourth and final phase, Development, game developers develop the narrative DGBL, and deployment of the final narrative DGBL (e.g., through a website, an LMS, etc.).

\section{The eLuna Visual Language}

The eLuna visual language has been developed to support the codesign and co-specification phases. By employing colour coding for different ontologies, red for Agents, green, blue, and purple for World, orange for objects, and purple for events, and additionally, graphical notation to indicate elements for all ontologies, the eLuna visual language provides a structured way to describe a narrative DGBL. In the design phase a simplified and flexible version of the visual language is employed, meaning that the participants can, if they need, resort to other descriptive techniques so as not to stop the work due to expressive difficulties or ambiguities. In the specification phase a complete and strict version of the visual language is employed, ensuring that all narrative DGBL elements are unambiguously described. The next four sub-sections present and describe the elements of the eLuna visual language ontology by ontology in the sequence that they are used in the eLuna framework design phase: Agents, World, Objects, and finally Events.

\section{The eLuna Visual Language: Agents}

Agents constitute the characters of the narrative DGBL. Agents are drawn as persons using red notation colour, and in the design phase, eLuna co-designers create biographies for them each on a separate paper. The biographies are free form, and contain the personal details of the agents, as well as a description of their role in the narrative DGBL such as which responsibilities and authorities they have, and their skills and competencies related to the learning objectives. To enable grounded and consistent agents, they are also described in terms of personality, such as their goals in life, their worries and fears, and their social and personal lives. Figure 2A shows the visual language elements available for the grounded and consistent agent category; eLuna Agent base shape and the four functions they can have in a narrative DGBL. These elements are employed in the specification phase.

As Figure 2A shows, in the visual language agents have a base shape and four features that describe the actions the agents can perform in the narrative DGBL: they can participate in dialogues with other agents; they can provide or receive information from other agents or by exploring the world and the objects in it; they can inspect or find agents and objects; or they can use objects or give objects to other agents.

\section{The eLuna Visual Language: World}

Worlds are constructed as a set of hubs that are drawn as green circles and labelled and named sequences of tasks drawn as blue circles. Tasks are combined in logical sequences to identify narrative DGBL quests, which are labelled and drawn as purple lines connecting several tasks. Hubs constitute relevant areas in the world where agents can exist and work to solve quests enabling learners to complete the game by completing tasks related to learning objectives. Figure $\mathbf{2 B}$ shows the visual language elements available for the world category, consisting of Hubs (where things can happen), and Quests (sequences of tasks that can be completed there). These elements are used throughout both the co-design and co-specification phases.

An eLuna world comprise several hubs, all with one or more quest attached to it, drawn using the elements shown in Figure 2B. The quests comprise one or more task that must be completed in a particular order. In eLuna narrative DGBL, learners can explore several hubs and quests in parallel.

\section{The eLuna Visual Language: Objects}

Objects are drawn as orange boxes and labelled to indicate what they represent. In the eLuna visual language objects can serve four purposes. Two objects can be combined to form a new object (such as adding a seed to soil to get a sprout), or an object can be inserted into another object to alter the purpose (such as changing the bore or screwing bit on an electric drill). Objects can also be 

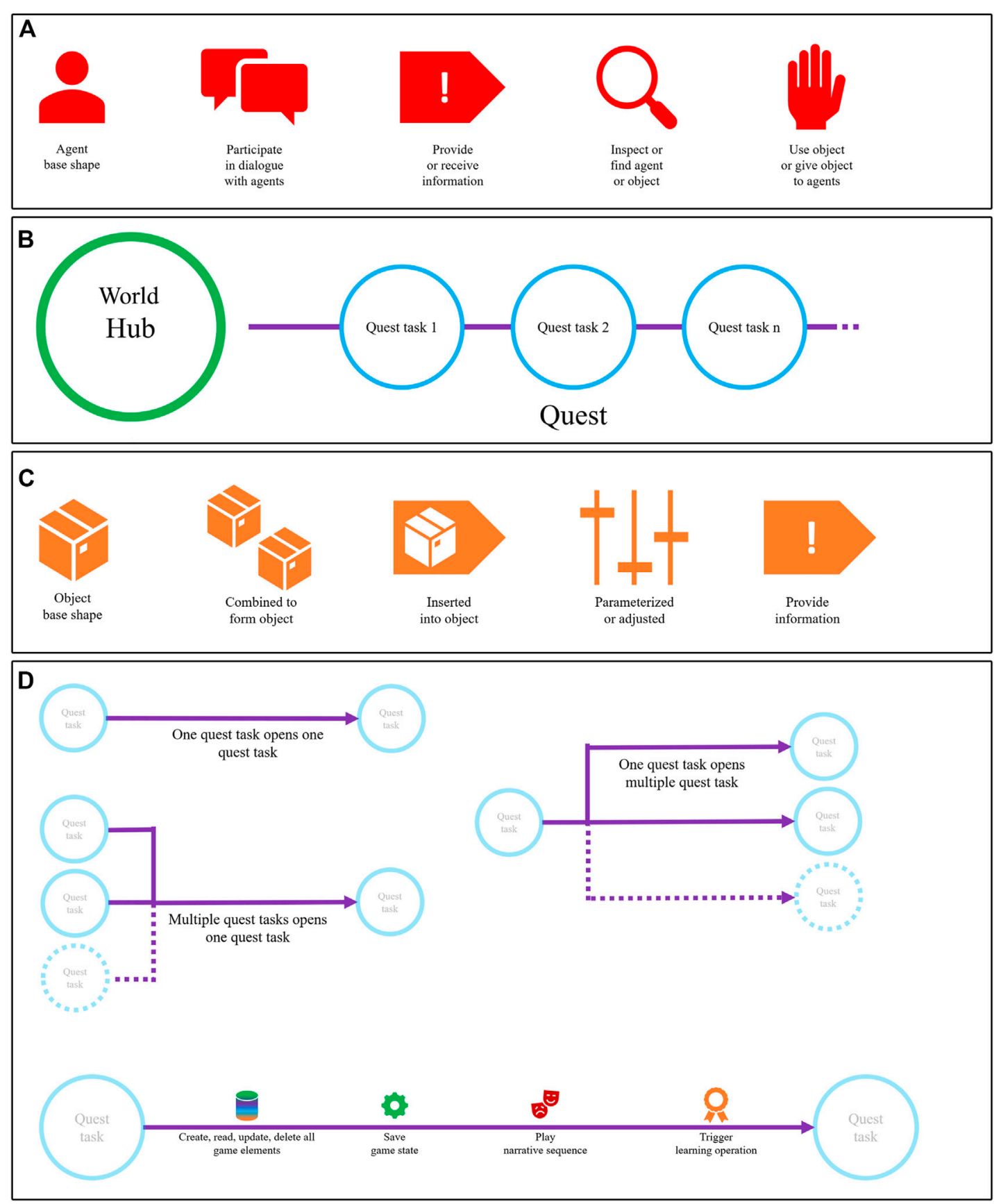

FIGURE 2 | The eLuna visual language.

altered (parameterized) to fit desired functionality (such as setting the program on a washing machine for washing different garments), or objects can provide information (such as searching for something in a browser and following links to relevant content). Figure 2C shows the visual language elements available for the modifiable objects category. In the co-design phase objects are listed using the elements, and in the cospecification phase the object elements are further used in combination with agents and other objects to specify their exact usage in quests tasks.
As Figure 2C shows, in the visual language objects have a base shape and four features that describe how they can be employed in the narrative DGBL: objects can be combined to form another object; they can be inserted into other objects; parameterized to provide a special functionality; or they can provide information.

\section{The eLuna Visual Language: Events}

Events are drawn as purple lines from tasks to other tasks and are triggered by a player's successful completion of quest tasks either by one task opening another, multiple tasks opening another, or 
by one task opening multiple tasks (see Figure 2D). The tasks that are opened can exist in the same hub and quest, in the same hub but a different quest, or in quests that reside in other hubs. Events are associated with defined learning objectives. As the narrative DGBL is played, it is through an event being triggered that the game unfolds and progresses. When events are triggered, all game elements can be manipulated, the game progress can be saved in the current state, narrative sequences can be presented, and outof-game learning operations can be directed. Figure 2D shows the visual language elements available for the events. These elements are used both in the design and specification phases.

Every time an event occurs, all elements (actors, hubs, quests, tasks, or objects) can be created, read, updated, or deleted in the narrative DGBL. Furthermore, the game state can be saved to conserve the progression and allow for breaks, and to provide data for learning analytics. At event occurrences, narrative sequence can also be defined and transmitted. Finally, the learner can be directed to complete learning objective related operations outside of the narrative DGBL, such as completing a quiz, submitting an assignment, participating in a group session, and similar.

\section{IDUN'S APPLES: THE ELUNA FRAMEWORK IN USE}

This section illustrates the use of the eLuna framework by one educator and two game designers to develop a narrative digital game-based learning (DGBL), Idun's Apples, from the preparatory work to the final game prototype. Idun's Apples is related to a learning program envisioned at the Bergen Science Centre $^{9}$ addressing UN Sustainability Goal 12: Responsible Production and Consumption ${ }^{10}$.

\section{Preparation}

The Responsible Production and Consumption program at VilVite focuses partially on a curriculum related to climate challenges from food produce production and logistics, and the opportunities and advantages related to local food production. The program is targeted at upper elementary and high school pupils. The learning objectives are related to the content areas: 1) climate gas emissions from food and produce production and logistics, 2) health regulations for food production and commerce, and 3) finances and economics related to sustaining local production and sales of produce. The learning situation is part of a threefold program structure where the narrative DGBL is intended to be part of a preparatory experience in which pupils explore the concept in a school's computer lab before visiting the science center to conduct related physical experiments using interactive science exhibits. The preparatory foundation for the further work on Idun's Apples is summarized as the following:

${ }^{9}$ The Bergen Science Centre (VilVite) is a partner in this research through the first author's industrial PhD grant from the Research Council of Norway (RCN).

${ }^{10} \mathrm{https} / / /$ sdgs.un.org/goals/goal12.
- Curriculum goal(s): Climate challenges from food produce production, and the opportunities and advantages related to local food production.

- Content area(s) and learning objective(s): 1) Climate gas emissions from food and produce logistics, 2) Health regulations for food production and commerce, and 3) Finances and economics related to sustaining local production and sales of produce.

- Learner demographic: Upper elementary and high school.

- Learning situation: Science center at school preparatory experience.

\section{Co-design}

During this phase the educator and the two game developers worked together using the information from Table 3 to design the agents, world, objects, and events. The phase begins with the educators presenting the information to the developers to establish a common understanding of the game context.

\section{Designing the Agents}

eLuna targets grounded and consistent agents, and these are described first. In the design phase, the co-designers focus on the details of the agents, who they are, their roles, responsibilities, and authority, their backgrounds, and their goals. As such, codesigners in the design phase do not use the elements of the visual language when describing actors, these details are added during the following specification phase. In the Idun's Apples game, the protagonist Idun was described first. Figure 3A shows how Idun is described in the design document that emerged from the design phase.

The co-designers also identified 13 additional agents for the narrative DGBL:

1. Idun's Son, Rubin: Happy and curious, with a mild asthma

2. Farmer's Market representative, Steinar: Organisational secretary with responsibility to assist development of local Farmer's Markets

3. Bureaucrat, Lars: Forgetful and overworked, not always on top of getting formal processes right

4. Politician, Hildegunn: Francophile and more interested in imports than local products. Likes good media coverage

5. Urban farmer, Lise: Advanced hobby grower selling produce on social media who is terrified of health regulations

6. Food and sanitation inspector, Günther: Would be FBI agent turned very thorough inspector in his hometown

7. Café owner, James: Wants to use local produce in kitchen but has little access. Very helpful with ideas and marketing

8. Librarian, Rikke: Very helpful with PR about Farmer's Market at the local library

9. Park owner, Konstantin: Has plot where Farmer's Market can be established

10. Supermarket clerk, Ivan: Thinks imported fruits are the best, since they taste sweeter than local ones

11. Supermarket clerk, Igor: Thinks local fruits are the best, since they taste more real than imported ones 
TABLE 3 | Co-designed eLuna narrative DGBL 1 through 6, elements identified by category.

\begin{tabular}{|c|c|c|c|c|}
\hline$\#$ & Grounded and consistent agents & Hubshaped quest landscape & Modifiable objects & Interchangeable fixed kernels \\
\hline 1 & $\begin{array}{l}\text { - The man in the woods } \\
\text { - The entrepreneur } \\
\text { - Politicians } \\
\text { - Construction workers }\end{array}$ & $\begin{array}{l}\text { - The man's farm } \\
\text { - The forest } \\
\text { - The build-site } \\
\text { - Town square } \\
\text { - Town hall }\end{array}$ & $\begin{array}{l}\text { - Physical barriers } \\
\text { - Traps } \\
\text { - Computer } \\
\text { - Car }\end{array}$ & $\begin{array}{l}\text { - The man making barriers and traps } \\
\text { - Meetings at town hall } \\
\text { - Meetings at entrepreneur } \\
\text { - Confrontations at the build-site }\end{array}$ \\
\hline 2 & $\begin{array}{l}\text { - The wife } \\
\text { - The husband } \\
\text { - The assassin }\end{array}$ & $\begin{array}{l}\text { - The married couples house } \\
\text { - The fishing boat } \\
\text { - Local bar } \\
\text { - Social media radical }\end{array}$ & $\begin{array}{l}\text { - Fishing equipment } \\
\text { - Assassins weapons } \\
\text { - Computer with social media }\end{array}$ & $\begin{array}{l}\text { - The husband going to and returning } \\
\text { from fishing } \\
\text { - Quarrel at the house } \\
\text { - Meeting at the bar } \\
\text { - Assassination } \\
\text { - Reading conspiracy theories }\end{array}$ \\
\hline 3 & $\begin{array}{l}\text { - The intern } \\
\text { - The reception clerk } \\
\text { - The ambulance driver } \\
\text { - The doctor } \\
\text { - Other nurses }\end{array}$ & $\begin{array}{l}\text { - Reception } \\
\text { - Ambulance arrivals } \\
\text { - Doctors office } \\
\text { - Operation theatre } \\
\text { - X-ray room }\end{array}$ & $\begin{array}{l}\text { - Registration tablet } \\
\text { - Medical equipment like bandages and casts, x-ray, } \\
\text { operating equipment, ventilators, stethoscopes, syringes, } \\
\text { medicine, and more }\end{array}$ & $\begin{array}{l}\text { - Arrival and registration of patients } \\
\text { - Sending patients to treatments } \\
\text { - Orders to assist treatments }\end{array}$ \\
\hline 4 & $\begin{array}{l}\text { - The old man } \\
\text { - Pupils } \\
\text { - Professionals encountered at } \\
\text { workplaces }\end{array}$ & $\begin{array}{l}\text { - The classroom } \\
\text { - The old man's apartment } \\
\text { - Professional places where work is conducted, e.g., offices, } \\
\text { bank, media station, fire department, hospital, school or } \\
\text { university, construction site, and so on }\end{array}$ & $\begin{array}{l}\text { - Any kind of equipment used in the professions that can be } \\
\text { explored, e.g., fire hoses, medical equipment, computer } \\
\text { programs, machines, and so on }\end{array}$ & $\begin{array}{l}\text { - Visiting the old man } \\
\text { - Talking to the old man } \\
\text { - Being sent to places by the old } \\
\text { man } \\
\text { - Performing work activities at } \\
\text { workplaces }\end{array}$ \\
\hline 5 & $\begin{array}{l}\text { - The girl } \\
\text { - Her mountain bike friends } \\
\text { - Politicians } \\
\text { - NGO manager } \\
\text { - Private investors } \\
\text { - Building entrepreneurs }\end{array}$ & $\begin{array}{l}\text { - Mountain bike tracks } \\
\text { - Club house plot } \\
\text { - Town hall } \\
\text { - Local NGO } \\
\text { - Girl's home }\end{array}$ & $\begin{array}{l}\text { - Bikes } \\
\text { - Construction materials } \\
\text { - Computer with internet } \\
\text { - Transportation means }\end{array}$ & $\begin{array}{l}\text { - Getting public or private funding } \\
\text { - Choosing building materials } \\
\text { - Constructing club house } \\
\text { - Using various forms of transport to } \\
\text { mountain } \\
\text { - Mountain biking }\end{array}$ \\
\hline 6 & $\begin{array}{l}\text { - The juveniles with various appearances } \\
\text { and concerns related to puberty } \\
\text { - Teachers } \\
\text { - Older kids } \\
\text { - Doctor and nurse }\end{array}$ & $\begin{array}{l}\text { - The classroom } \\
\text { - The schoolyard } \\
\text { - The locker room at the school gym } \\
\text { - The youths' homes } \\
\text { - At the doctors } \\
\text { - Social media platforms }\end{array}$ & $\begin{array}{l}\text { - Pop artifacts } \\
\text { - Fashion items } \\
\text { - The mobile phone } \\
\text { - Glasses } \\
\text { - Schoolbooks } \\
\text { - Food }\end{array}$ & $\begin{array}{l}\text { - Posting something on social media, } \\
\text { or seeing a post } \\
\text { - Having physical or mental } \\
\text { challenges caused by puberty } \\
\text { - Visiting the doctor } \\
\text { - Parent/teacher meeting }\end{array}$ \\
\hline
\end{tabular}



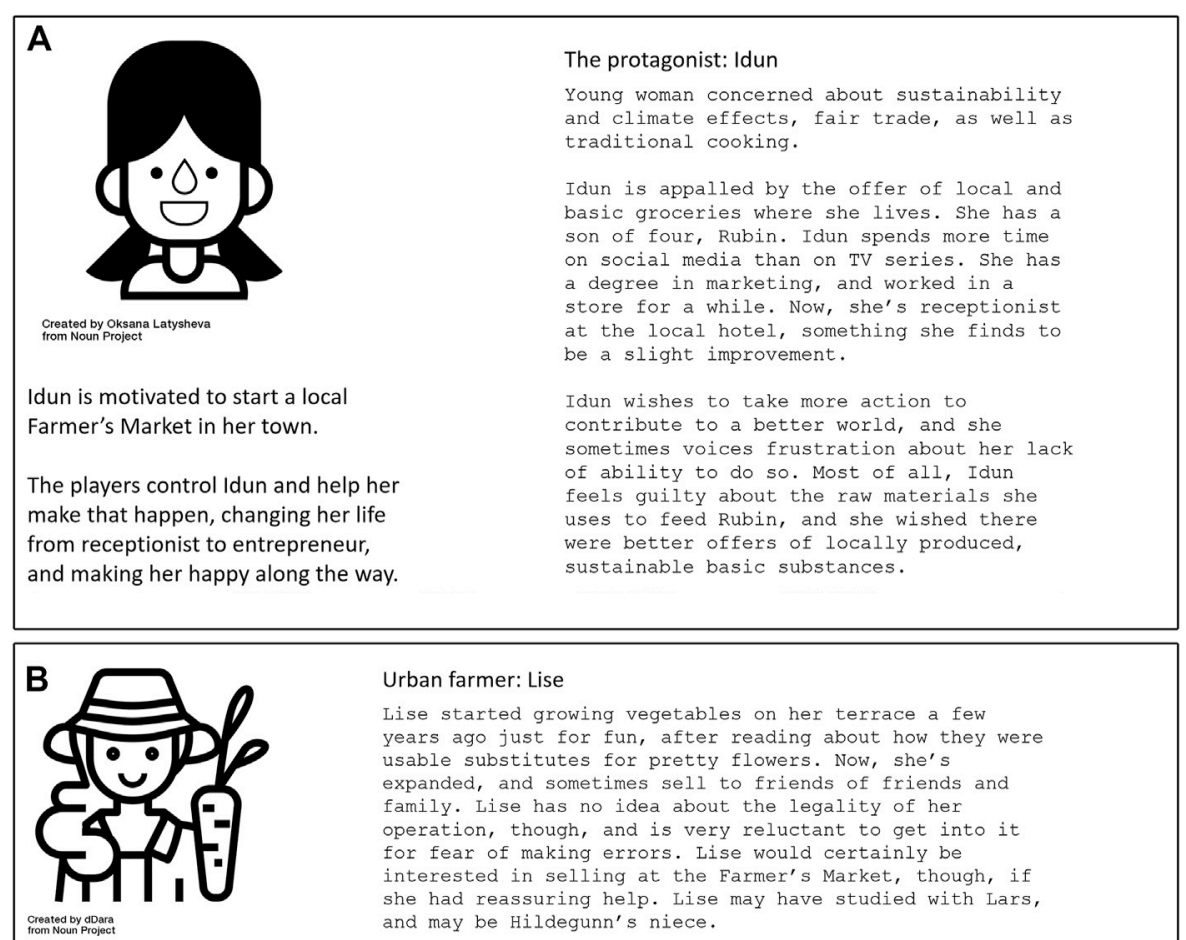

Lise started growing vegetables on her terrace a few. years ago just for fun, after reading about how they were usable substitutes for pretty flowers. Now, she's expanded, and sometimes sell to friends of friends and family. Lise has no idea about the legality of her Camily. Lise has no idea about the legality of her operation, though, and is very reluctant to get into it for fear of making errors. Lise would certainly b interested in selling at the Farmer's Market, though, if she had reassuring help. Lise may have studied with Lars, and may be Hildegunn's niece.

Food and sanitation inspector: Günther Gunther cherishes distrust, and always make sure to stock up on it. If it hadn't been for him not wanting to leave up on it. Tf it hadn't been for him not wanting to leave town, Gunther always envisioned himself an FBI agent. As inspector, though, he does get a badge, and permission to look around, Investigate, as he sees it. He also has the authority to stop things, something that he enjoys doing. Günther will always demand a bit more than regulations require, and Idun will always need to double verify everything. There is no way around it. Or maybe it is, if

$$
\text { Lise asks? }
$$

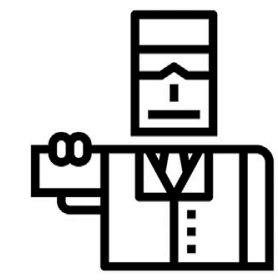

Created by Smallike
from Noun Project

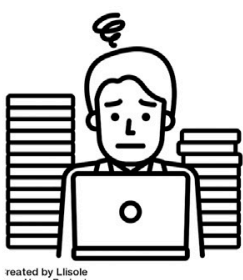

reated by Lisisole
om Noun Project

Bureaucrat: Lars

Lars is overworked, and is not in command of all the systems that he's supposed to be. Lars forgets things, but gets by organizing local government as long as everything is delivered to him completely and correctly. As long as Idun understands everything she needs to do, and prepare it all herself, Lars is benign, and will. process her requests and applications. If he needs to find something out, though, he pretty much shuts down and ignores her.

Local politician: Hildegunn Hildegunn is in a political position to be a main driver or road block for Idun. The problem with her is that she road biock for It cesn't see the need for a Parmer's Market locally, she ats her food at restaurants, and is more inclined to discuss hyperloop or drone delivery from France than local produce. She likes to brag though, so media coverage is a sweetener for her. It would help if she understood that local produce would benefit the quality of local restaurants too, and that the French might even

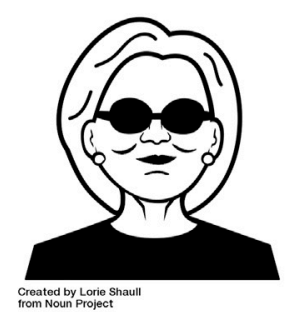

FIGURE 3 | eluna agents design phase.

12. Culture fund manager, Dina: Can support funding for events like the Farmer's Market, provided public support is also in place
13. Gallery owner, Sara: Can provide advertising in gallery store, and can initiate local arts and crafts stall at the market 

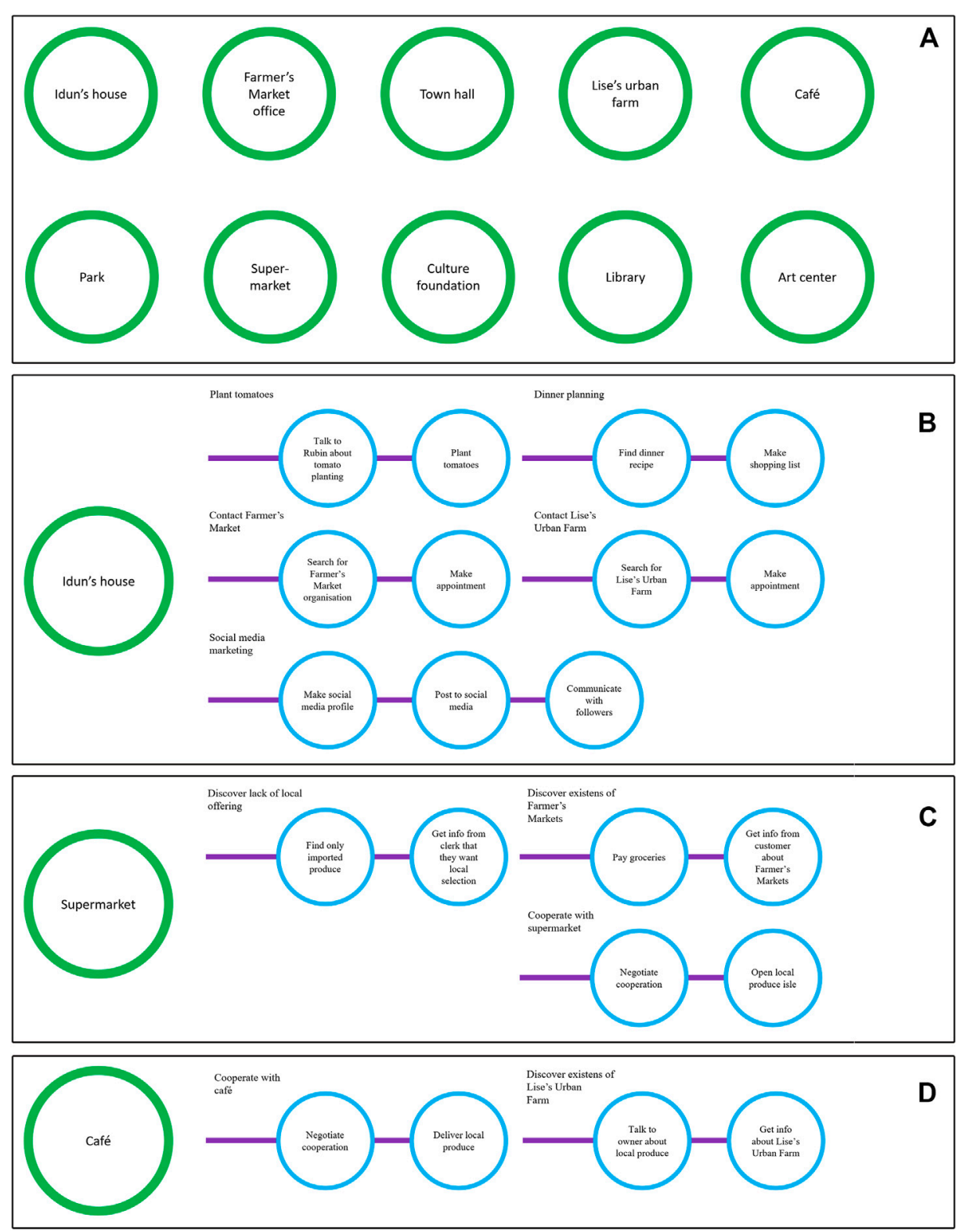

FIGURE 4 | eLuna hubs and quests design phase.

Figure 3B describes four of the agents in more detail.

\section{Designing the World}

In eLuna, the world is constructed as a set of locations (hubs) where sequences of tasks may be performed to reach objectives (quests). Co-designers are encouraged to brainstorm hubs and to define quests that logically belong at the locations. Then, in as much detail as possible, the quests are broken down into sequences of tasks that must be completed in sequence to complete the quest. In Idun's Apples, the co-designers identified 10 hubs of relevance, shown in Figure 4A.

In the next step, the co-designers identified 27 quests related to the 10 hubs. The quests were broken down from between one and three tasks per quest (there are no minimum or maximum number of tasks in quests, this was only the range that came out of the Idun's Apples design phase), resulting in a total of 63 tasks in the game. Figure 4 (B through D) shows the developed quests for Idun's house (B), the supermarket (C), and the café (D).

As seen from Figure 4 (B through D), ten quests totalling 21 tasks are identified under the three hubs Idun's house, Supermarket, and Café. At her house, Idun can 1) plant tomatoes with her son Rubin, 2) plan dinner for the two of them and make a shopping list, 3) use the Internet to find out about the Farmer's Markets organization and contact it, 4) use the Internet to find out about Lise's Urban Farm and 


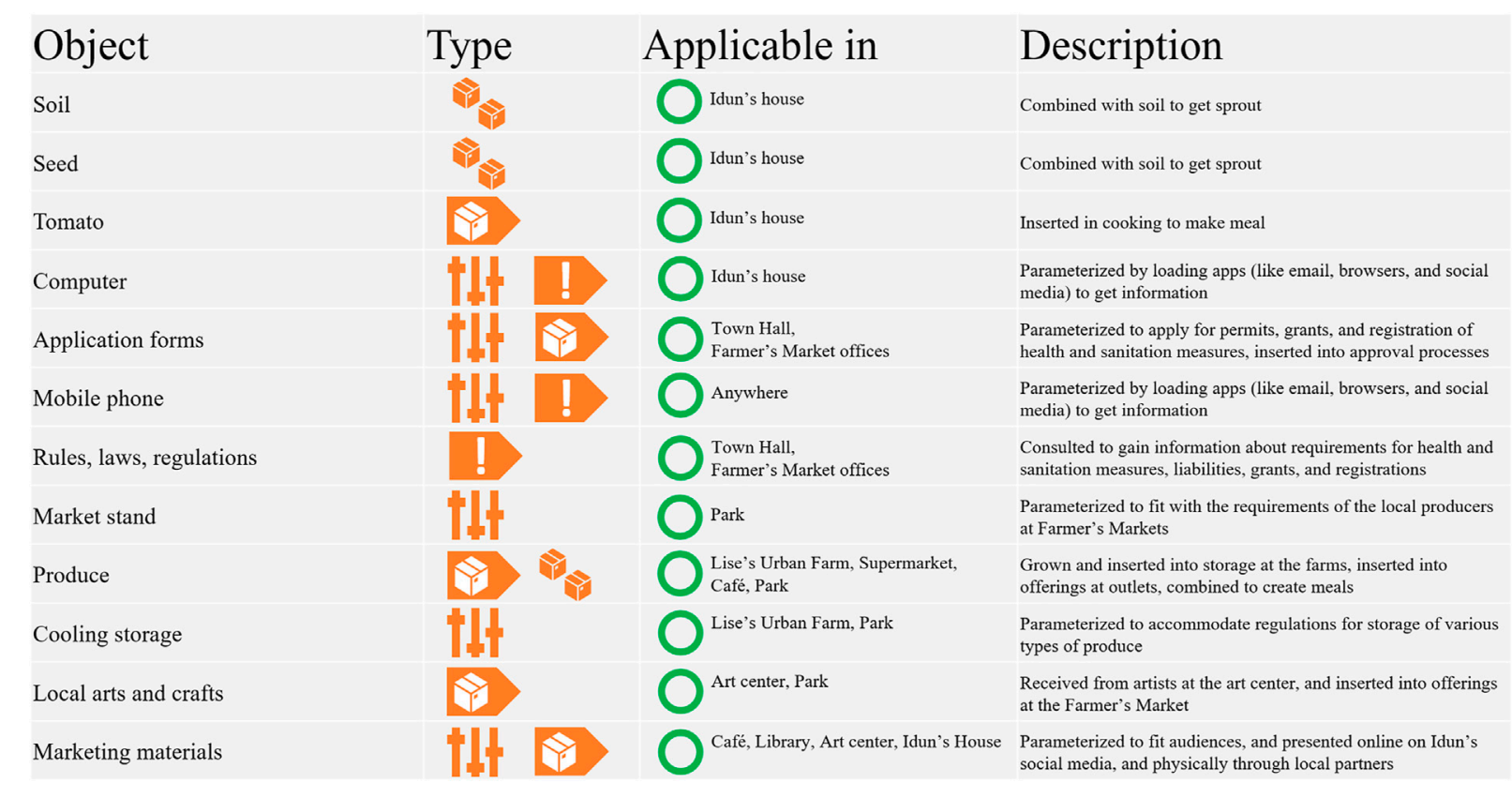

FIGURE 5 | eLuna objects design phase.

contact her, and 5) create and manage a social media page to market her own local Farmer's Market initiative. At the Supermarket, Idun can 1) discover that there is no local produce available, 2) learn that there exists a central organization to help facilitate local Farmer's Markets, and 3) make a deal with the Supermarket to sell local produce once supply has been established. At the Café she can 1) learn about the existence of Lise who has an urban farm from which she sells local produce on the Internet, and 2) as with the Supermarket, establish a deal to supply the café with local produce. Including those three shown in Figure 4 (B through D), the following quests were designed for the following hubs in the game:

- Lise's house: Plant tomatoes, Dinner planning, Contact Farmer's Market, Contact Lise's Urban Farm, Social media marketing

- Supermarket: Discover lack of local offering, Discover existence of Farmer's Market, Cooperate with Supermarket

- Café: Cooperate with Café, Discover existence of Lise's Urban Farm

- Farmer's Market central office: Learn public health and sanitation requirements, Learn Farmer's Market policy, Incorporate as Farmer's Market, Approve Lise as vendor

- Town Hall: Get approval for Farmer's Market, Incorporate legal business, Get health and sanitation approval, Apply for public grant

- Lise's Urban Farm: Learn about Lise's life, Health and sanitation preparation, Farmer's Market policy preparation

- Park: Visit Park, Secure venue for Farmer's Market, Health and sanitation preparation, Hold first Farmer's Market
- Culture foundation: Apply for culture fund grant

- Library: Make deal for PR

- Art Center: Make deal for sales stall

The individual tasks in the quests are left out of the above list, however, they are described in Section 4.2.5 where the full design for Idun's Apples is shown.

\section{Designing the Objects}

eLuna places emphasis on objects that can be modified in three ways: combinable, insertable, or parameterizable. Furthermore, objects can provide information, be observed by agents, used by agents, or given by agents to other agents. During this step, codesigners are encouraged to identify as many objects as possible that are applicable for the game, define their types, and indicate in which hub these objects belong if any, as some objects, like mobile phones or credit cards, can be carried around and used many places. When designing Idun's Apples, the co-design process resulted in 12 modifiable objects. Figure 5 shows the object definitions, their type, where they are applicable, and their general description.

As seen in Figure 5, objects can be of one or more type, and can be applicable in one or more hub. The description of the objects in the co-design phase is used in the co-specification phase to identify exactly how they are applied by whom, where, and at what time.

\section{Designing the Events}

The final step is to design the events. eLuna events are interchangeable and fixed, meaning that they are pre-written (fixed), and that they can be observed by the players in various 

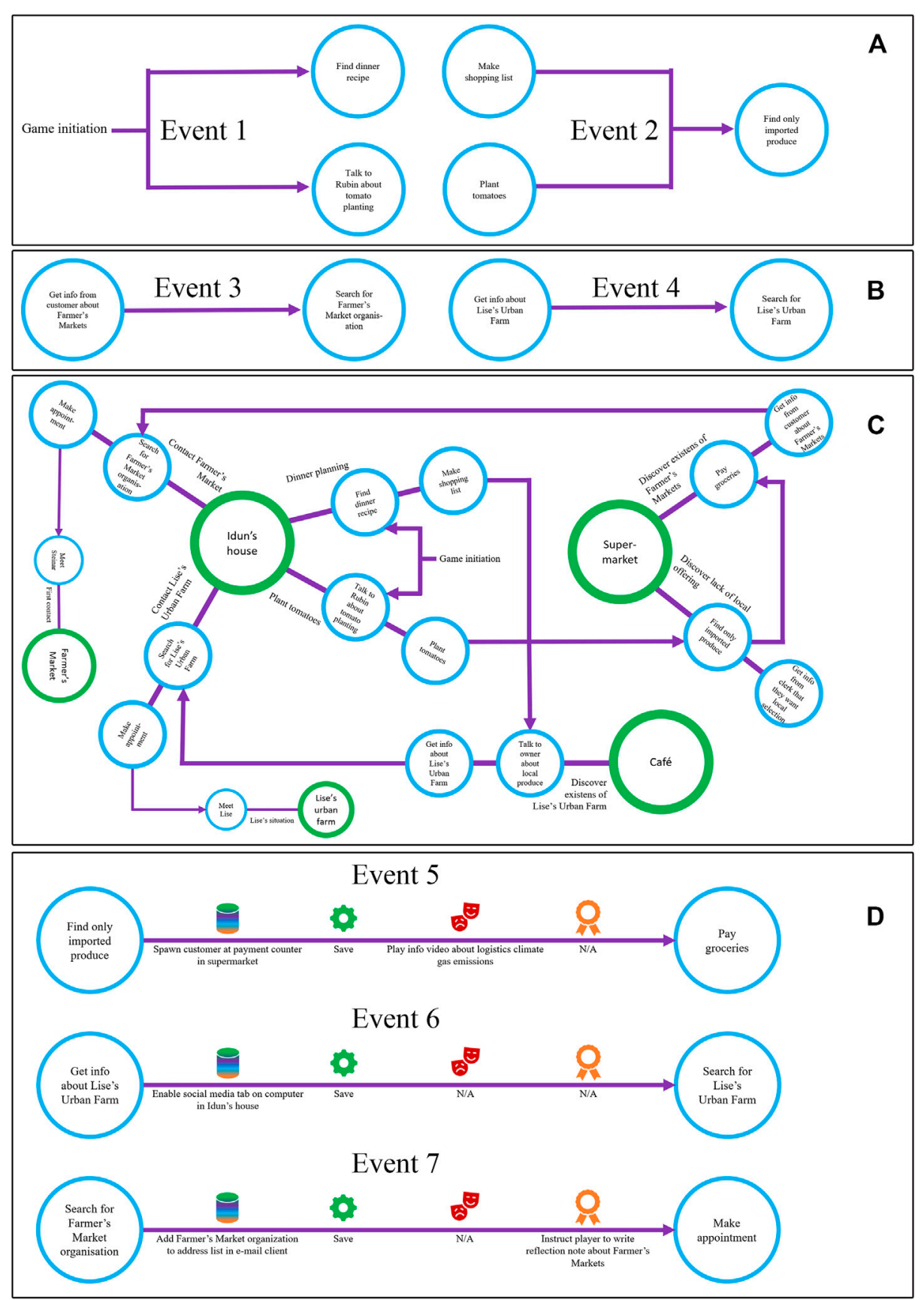

FIGURE 6 | eLuna events design phase.

sequences from play through to play through (interchangeable), depending on how different players decide to proceed with the game. Revisiting the design of the world (chapter 3.2.2), the first events to be identified are all the lines that have been drawn between tasks belonging to the same quests. Further events are identified by examining the logic of the game that has been designed so far and using the visual language lines to draw events as they occur between tasks that belong to different quests in the same hub or in other hubs. At the start of events design, a special one-off event that initiates the game is defined, pointing to all tasks that will be available when a player starts a new game play session.

For the Idun's Apples world design, it is known that Idun wants to plant tomatoes with Rubin and make a shopping list for dinner. The co-designers decided to allow both quests to be available at game start, and that both should be completed before Idun can go to the supermarket to make her purchases. At the supermarket she will discover that the supermarket only carries 
imported goods. As shown in Figure 6A, the above logic identifies two new events; the first (Even 1) is an event that starts by initiating the game, opening the first two game tasks, the second (Event 2) is completing two different tasks to open a new task.

At the supermarket, Idun also gets the opportunity to learn about Farmer's Markets from a fellow customer, which is a oneto-one event (Event 3) opening a task allowing her to search for information about Farmer's Markets on the computer in her house. Similarly, the co-designers decided to allow Idun to visit the café, where she can talk to the owner and learn about Lise, a conversation leading to another one-to-one event (Event 4), opening a task at her computer where she can search out Lise on social media. Figure 6B shows the two one-to-one events.

In the Idun's Apples design, the co-designers mapped out events to the point in the game where Idun travels to meet Steinar at the Farmer's Market, and Lise at her Urban Farm, as this was as far as the narrative DGBL prototype would be implemented. Figure 6C shows the full set of events identified by the codesigners through linking quests tasks together, leaving out three quests that are shown in addition in Figure 4 (C through D) (cooperate with café, cooperate with supermarket, and social media marketing) since these do not become available until Idun has done other quests after meeting with Steinar and Lise.

As seen from Figure 6C, eLuna supports interchangeable fixed kernel events. Two quests are opened when the player starts the game, and they can be explored in any sequence. After each task an event is triggered. Furthermore, following the event paths through the structure reveals that Idun may visit the supermarket and the café in any order, and that the information received from agents at either of the hubs can be explored further as the player wants to go about it. The visits to the Farmer's Market and Lise's Urban Farm can be completed in any sequence, in fact, it's possible for Idun to complete contact and visit to one of these, without even knowing about the other. Notice that a quest does not have to be completed to trigger an event to a new task in another quest, as seen by the route straight to the payment counter after finding the imported produce. Idun can also talk longer to the clerk to learn that the supermarket would be interested in local purchases.

After identifying and connecting all events in the design, the co-designers carry on using the visual language to indicate what the individual events causes. The events are listed as connected through tasks, and details are provided. For example, when Idun has found imported produce and is ready to pay, the co-designers want to move a fellow customer to the payment counter so that Idun can have the talk about the Farmer's Market, save the game, and play a narrative sequence about climate gas emission from logistics. Equally, when Idun has received information about Lise at the café, they want Idun's computer at home to get a social media tab under its browser where Lise's Urban Farm can be found and save the game. Once the Farmer's Market organization has been found, they want to allow Idun to send them an email through her computer's mail client, save the game, and instruct the player to leave the game to complete a reflection note about Farmer's Markets based on what they have discovered so far. Figure 6D show these three events and append them with visual language structures for including the above.
The three examples show events can go from tasks in different quests in the same hub (Event 5), from tasks in quests in one hub to tasks in quests in other hubs (Event 6), and from one task to the next task in the same quest (Event 7).

\section{Summary of the Co-Design Phase}

Whereas Figure 6C shows the quests and events that will be worked on through co-specification and prototype development phases (and is the delivery from the co-design phase), the codesigners actually designed a full quests and events structure for the Idun's Apples game, The full Quest and event structure for Idun's Apples, that illustrates the full potential and complexity of eLuna designs, is included in the supplementary materials for this article.

With regards to game structure, The full design in the supplementary materials differs from Figure $6 \mathrm{C}$ in three details: 1) it shows planting tomatoes and making shopping list as one quest, which was altered later since it gives more flexibility to the player, 2) it only opens the café after Idun has been to the supermarket, in the later version both become available at the same time, also to allow more flexibility, and 3) it shows Idun learning about both the Farmer's Market and Lise's Urban Farm when visiting the supermarket, which in the later version was changed to Idun learning about Lise at the café, a place where the co-designers felt it was more natural that Lise would have connections. The full design in the supplementary materials also shows the full game unfold where Idun learns everything she needs about Farmer's Markets legalities and policies, and goes on to organize, finance, and promote one, before successfully opening a Farmer's Market in a park in her town.

\section{Co-Specification Phase}

In the co-specification phase, the co-designers employ the full eLuna visual language to create a strict and unambiguous blueprint of the narrative DGBL to a point where it can be developed and deployed for the learner demographic. The cospecification phase involves four steps. First, hubs and quests are revisited to ensure that all events can be followed in a logical manner, and that all tasks are programmable. Second, the actors and objects visual language elements are added to tasks to show clearly what is used by whom, when and where. Third, concrete dialogues are added to tasks. Fourth, narrative passages are added to events.

\section{Revisiting eLuna Hubs and Quests}

In this step, co-designers inspect the event flow of the eLuna design, and ensure that everything can be reached in a logical manner, and that everything that happens is clearly and unambiguously described for programmers to make a narrative DGBL from the design. In the Idun's Apples design, consider the two quests 'Contact Farmer's Market' and 'Contact Lise's Urban Farm'. Both end in tasks where Idun can make appointments, which trigger events where she can visit one of two new hubs where she is introduced to either Steinar or Lise. A question arose about how she gets there. eLuna narrative DGBL targets hubshaped quest landscapes and use interchangeable fixed kernel events, so Idun should not be immediately transported to 

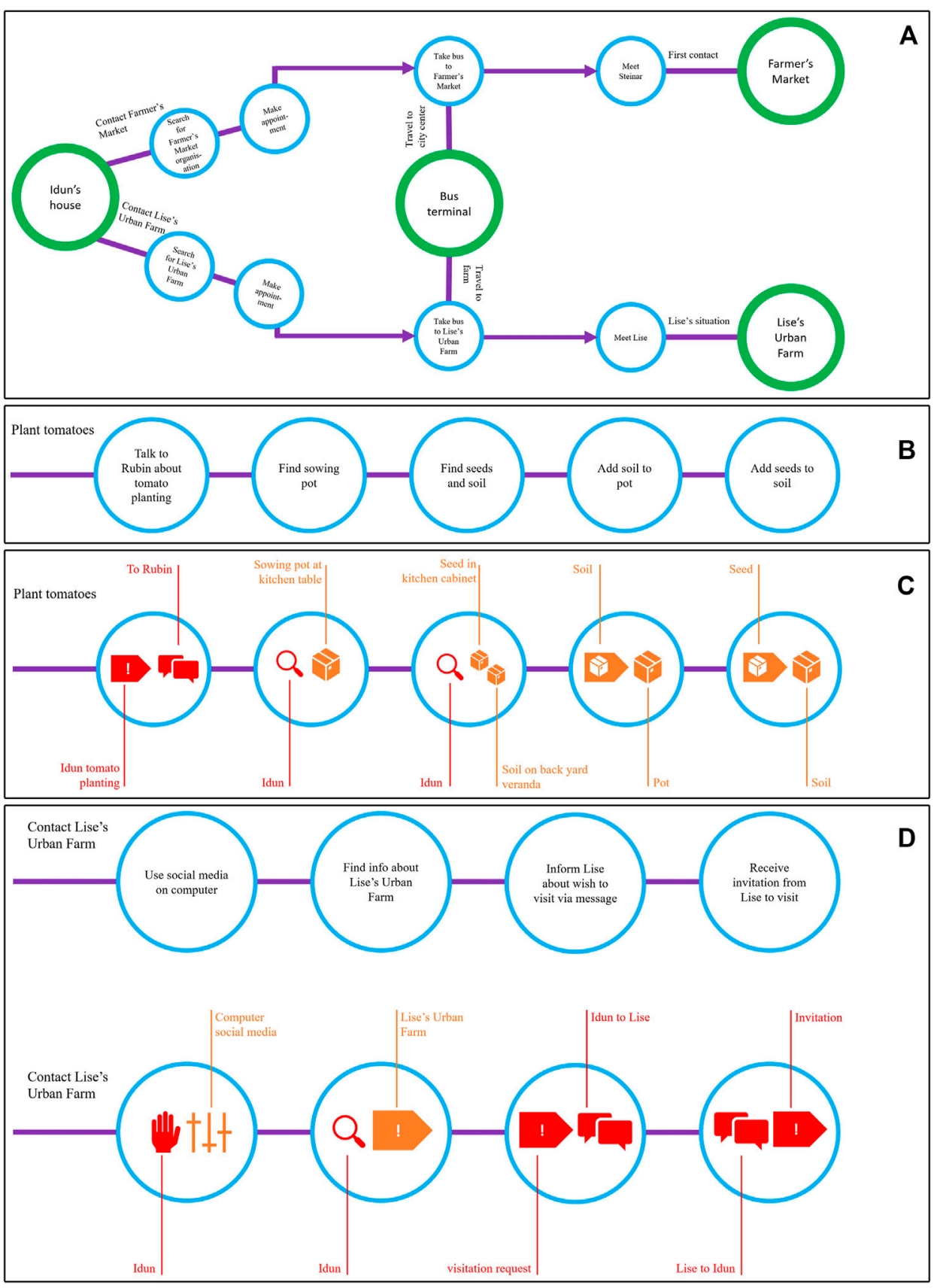

FIGURE 7 | eLuna revisit hub quests, add objects and agents to tasks.

these locations after appointments have been made. Rather, she should be able to get appointments set up, but then be free to explore the world (e.g., visit the café if she has not already done so after being at the supermarket), heading to the newly opened hubs at her own leisure and time. The co-designers decide that it is plausible that Idun could reach both hubs by bus, so they add a bus station as a new hub in the game, as shown in Figure 7A.

After scrutinizing the design and adding hubs as needed the co-designers focus on the quests that have been designed and break them down into tasks that each have unambiguous meanings. The quest 'plant tomatoes' consists of two tasks: 1) Talk to Rubin about planting tomatoes, and 2) Plant tomatoes. A question arose about how the second task 'plant tomatoes' is carried out in detail, since as it stands it is not a description that can be unambiguously programmed. To resolve this, the codesigners revisit the design's agents and objects, and use them to divide the single task into an unambiguous string of tasks. Figure 7B shows the new plant tomatoes quest. 


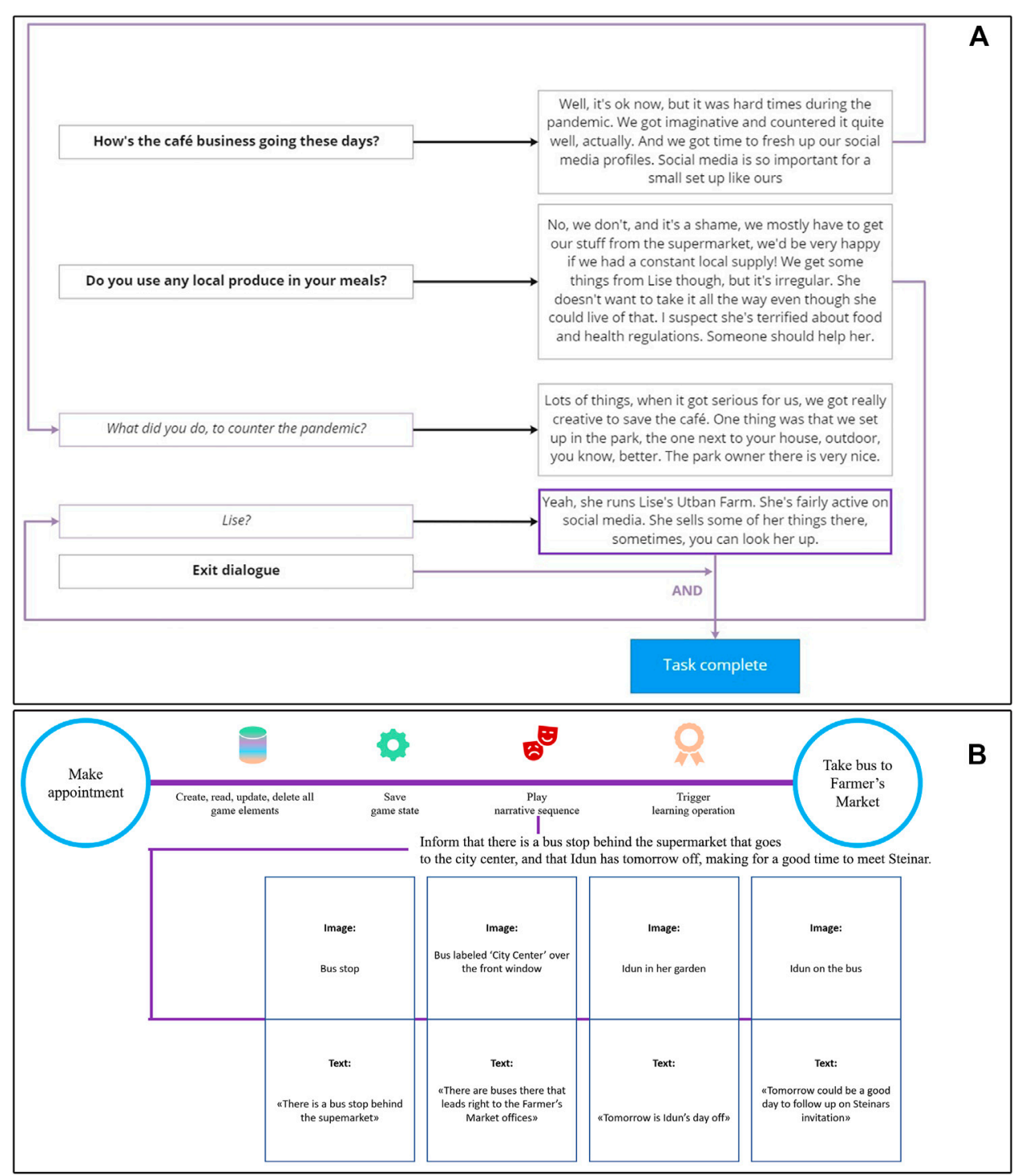

FIGURE 8 | eLuna specifying dialogues and adding narrative sequences.

\section{Adding eLuna Visual Language Agents and Object Elements to Quest Tasks}

After dividing tasks in quests as shown in Figure $\mathbf{7 B}$, the blueprint also needs to specify all the elements inside the tasks by defining who does what when and where. This is done by exchanging the task text with the elements of the visual language for agents and objects, making pairs of them, annotating which objects and agents are involved in the task, and where the objects and agents are in the related hub. Revisiting the plant tomatoes quest, the co-designers observe that Idun and Rubin are involved in the conversation in which Idun informs Rubin about the planting task. The sowing pot is in Idun's house, and it was decided to be more precise and indicate that it be located on Idun's kitchen table. The seeds are determined to be in her kitchen cabinet, and the soil on the veranda in her back yard. Figure 7C shows the complete specification with added objects and agents to tasks that will appear in the blueprint for the plant tomatoes quest, using the annotated eLuna visual language.

To show the remaining elements of the agents and objects visual language in use, Figure 7D (top) shows how Contact Lise's Urban Farm is broken down to unambiguous quest tasks in which 1) Idun opens social media on her computer, 2) Idun searches for and finds Lise's Urban Farm, 3) Idun informs Lise about her desire to visit, and 4) Lise responds with an invitation, and illustrates how it will be specified in the blueprint (bottom).

\section{Specifying eLuna Dialogues}

eLuna dialogues occur as part of quest tasks and are conducted between agents. In eLuna, dialogues are created by co-designers as trees in which a player-controlled agent engages another agent in conversation, selecting from an initial set of dialogue lines. Once dialogue lines have been communicated, they vanish from the options, 


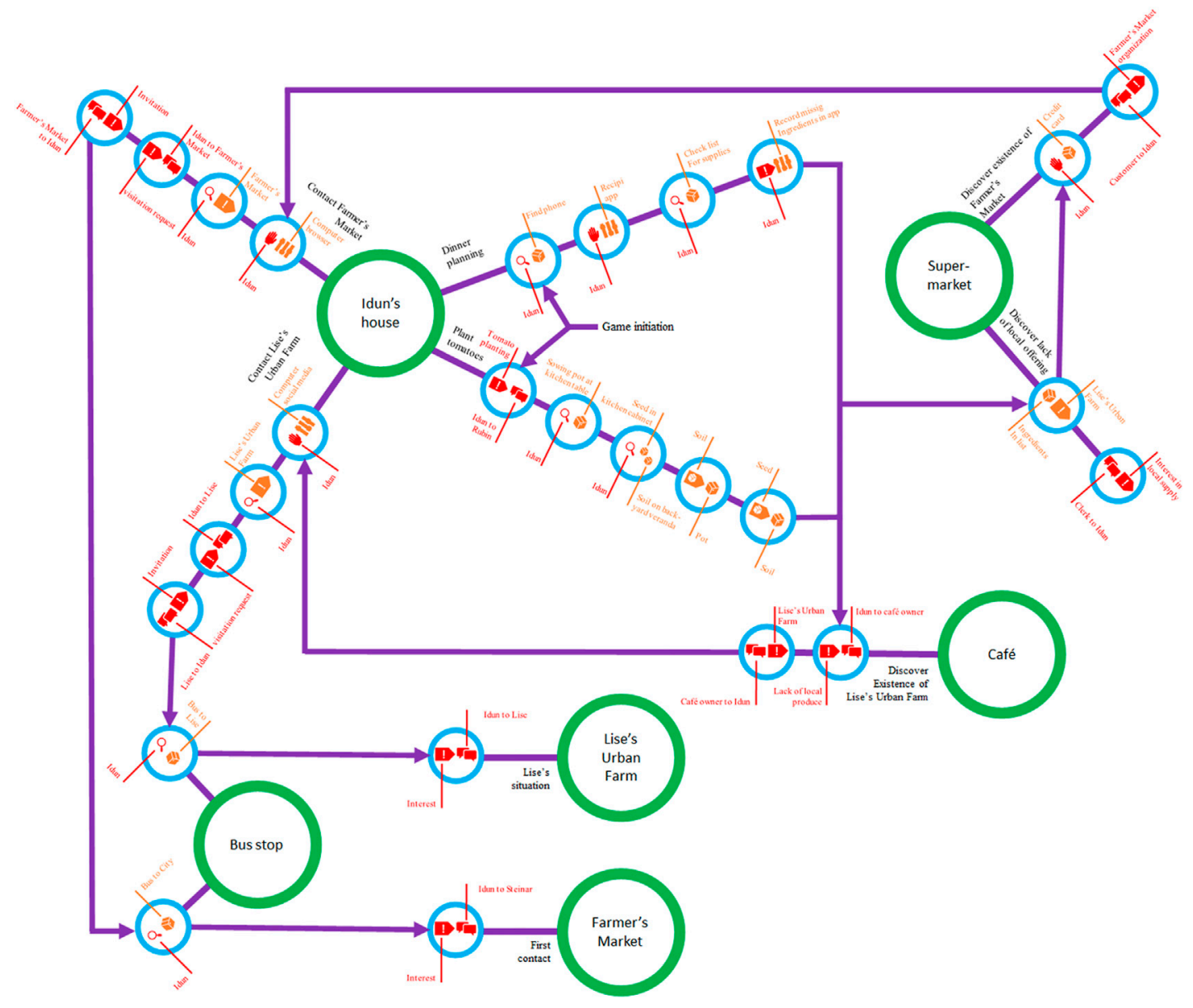

FIGURE 9 | Idun's Apples blueprint.

and may be replaced by new dialogue lines, naturally emerging to follow up the conversation as new information is brought up. If dialogues end, they restart from the beginning the next time the agent is engaged. Figure 8A shows a dialogue in which Idun engages the café owner and learns about the existence of Lise's Urban Farm.

In the dialogue, lines that are available at the start are highlighted in bold, and lines that may be made available later are in italic. A single statement has a single response, indicated with a black arrow. New lines are made available after responses are presented, indicated by purple arrows. From the example in Figure 8A, it can be seen that Idun needs to ask if the café uses local produce to first hear about Lise. By following up, Idun learns about the Urban Farm and how Lise has a presence on social media. Once that response is received, and the dialogue has been actively ended by Idun, the task is completed, and the event leading out from it is triggered. Idun does not need to ask the café owner how business is going and follow up on the conversation about the pandemic (indicated by italics). However, as seen, the response that comes from that line hints that the park owner is helpful, something that will be important information later in the game, once Idun is ready to look for a location for her own Farmer's Market.

\section{Adding eLuna Narrative Sequences}

The events in eLuna have integrated narrative sequences as shown in Figures 2D, 6D. These are briefly described by the co-designers when designing the events, and in the cospecification phase they are revisited and detailed to completion. Different narrative DGBL can resort to different media formats for these. For example, they can be video sequences, often referred to as cut-scenes in video games, they can be text only, audio, or animated clips, all depending on the project's resources and art direction. In Idun's Apples, the narrative sequences are determined to comprise sequential panels showing pictures accompanied by text. In narrative DGBL these sequences play two roles; they drive the story forward and provide hints and instructions to guide the player onwards to new tasks that need to be accomplished. Figure $\mathbf{8 B}$ shows the task named 'Make appointment' (from the Contact Farmer's Market quest) that leads to the 'Take bus to Farmer's Market' task (from the Travel to city center quest). Here the co-designers now define a detailed narrative sequence fitted to the narrative DGBL's art direction. 

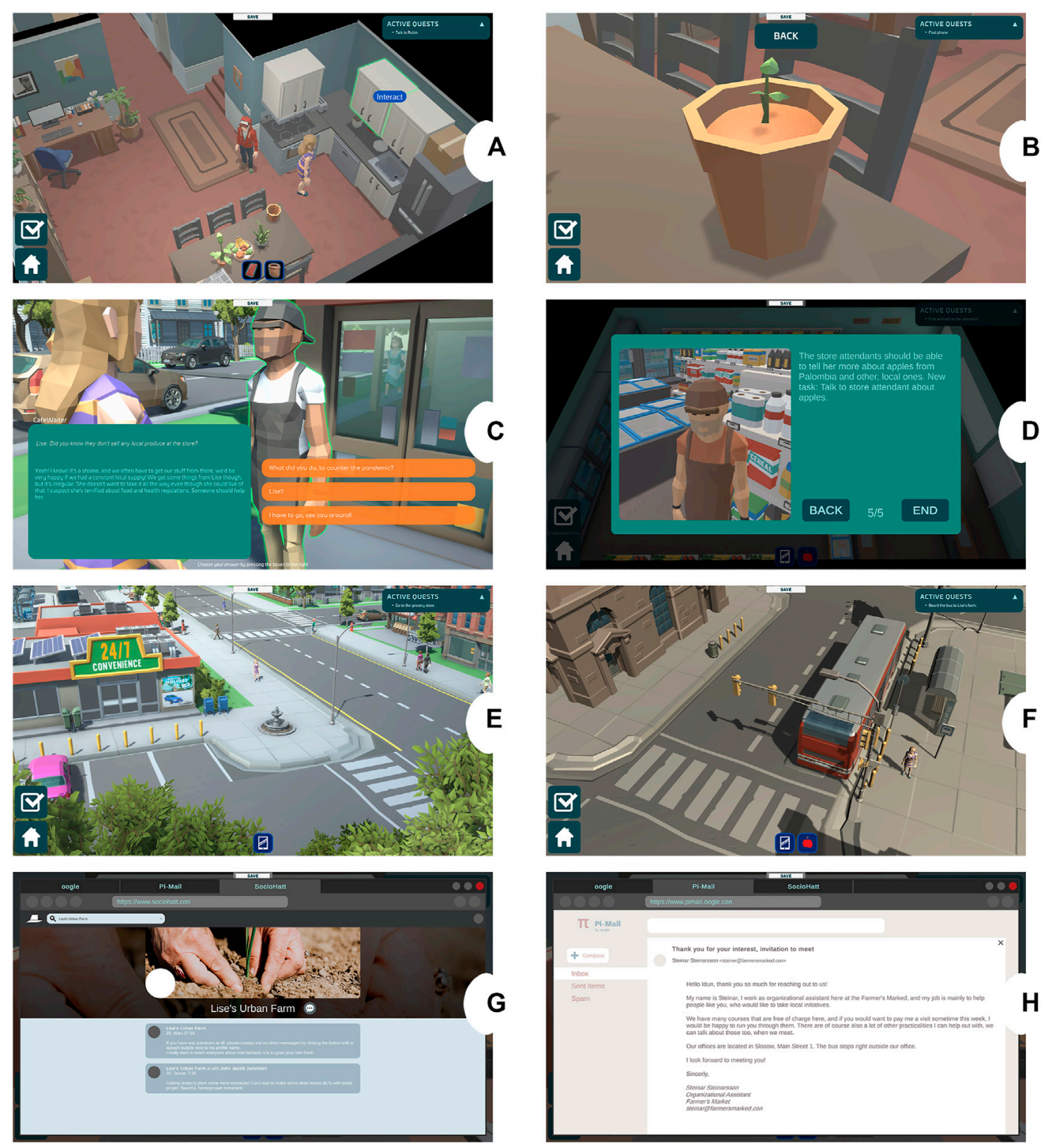

FIGURE 10 | Iduns Apples prototype screenshots.

\section{Idun's Apples Blueprint}

Figure 9 shows the Idun's Apples blueprint after revisiting hubs and quests and adding agents and objects to tasks using the strict visual language. The blueprint is used to develop the Idun's Apples prototype, which is described in the next section.

Compared to Figure 6C, Figure 9 contains one additional hub, the Bus stop. The number of quests is increased from 9 to 11 with the addition of two new quests at the bus stop, and the number of tasks has increased to 16 to 27 as more detail was needed to make a blueprint that unambiguously specifies a narrative DGBL that can be implemented. All conversations in tasks and all narrative sequences in events, were further specified as exemplified in Figures $\mathbf{8 A}, \mathbf{B}$. These specifications are available from the authors on request.

\section{Development Phase}

During this phase the blueprint for Idun's Apples is developed by the game developers into a narrative DGBL prototype ${ }^{11}$. Figure 10 show eight scenes from the developed prototype, conforming to the blueprint from the specification phase:

- (A) Idun in her house with her son Rubin, interacting with a cabinet,

\footnotetext{
${ }^{11}$ To demonstrate all elements of eLuna, and to accommodate for time and development costs of the project, only three of the hubs (vertical slice in game development terms) have been developed.
} 
TABLE 4 | Brief description of the co-designed eLuna narrative DGBLs.

\# Participants Curriculum

1 Three Technology Enhanced Learning General sustainability (no particular (TEL) experts

2 Three TEL experts

\section{Two high-school teachers. One game Career counselling} developer

5 Two secondary to high-school museum teachers. One TEL expert (same as in 1). One university college teacher. One game developer

6 Three secondary to high-schoo museum teachers. One university college teacher.One game developer (same as in 4) subjects' curriculum, since the practitioners

General sustainability (no particular subjects' curriculum, since th participants are TEL experts and not practitioners)

Health care management and administration

Regional sustainability

Human biology

assistance tasks and

\section{Learning objectives}

Consequence of

deforestation

- Democratic processes

- Civil disobedience

Consequences of

overfishing

- Internet extremism

- Ecologism

- Emergency room diagnostics and prioritization

- Nurse medical

responsibilities

- Career path options and required education/ skills

- Workplace tasks and

responsibilities

- Nature conservation

- Sustainable

construction and

engineering

- Accessibility

- Adolescent
development
- Social stigma
- Medical diagnostics

- Adolescent

and treatment

\section{Demographic Learning situation}

University bachelor

level

\section{Synopsis}

Envisioned for students to play as preparation for group discussion

University bachelor Envisioned for students to play as leve

Envisioned for students to play as
preparation for group discussion

High-school level

Played as homework before and after classes concerning related topics through the semester

High-school level

Played in class, while discussing career options and educational paths

Elementary and

high-school levels

Played before or during class visits to the science center, in combination with exploring the same topic using interactive exhibits

Elementary and high-school levels

Played before or during class visits to the science center, in combination with exploring the same topic using interactive exhibits
With goal to protect local flora and fauns a man living in the forest resort to politica processes and civil disobedience to prevent a local build-out project

A wife goes eco-extremist after following dark-web influencers and hires an assassin to kill her husband because he is a fisherman, and she decides that he is part of the global sustainability problem

A newly educated nurse interns at a hospital emergency room, aiding diagnostics, and prioritization of patients as they arrive, and assist procedures with doctors as required based on the diagnostics and prioritization

Learners visit an old man living in their school's basement who has had all jobs imaginable. The old man has a magic ability to send the learners into any workplace that he has held, where they can experience the realities of performing various jobs

A young woman establishes a mountain biking club, before commencing to plan and build a club house and tracks at a local mountain, taking care to perform a processes as sustainable as possible, while still allowing bikers to access the tracks in an uncumbersom manner

Illustrating various challenges of adolescents going through puberty, and, through depicting social problems arising from them, explains the biologica reasons for human development from child to adult 
- (B) a close-up screen resulting from her combining soil and seeds in a pot to sprout a tomato

- (C) Idun talking to the café owner, learning from him that he would gladly purchase local produce if more were available, that there is a woman called Lise that grows vegetables, that Lise needs help to increase production,

- (D) a narrative event screen tasking Idun to talk to a store clerk about imported apples,

- (E) Idun on the street, walking between Hubs with the supermarket in front, the bus station behind it, the café on the other side of the street, and her house up the road behind the café,

- (F) her arrival in the city center, to where she can take the bus when she wants to visit central farmer's market organization, town hall, and other agencies,

- (G) Idun having found Lise's Urban Farm on social media, from where she can contact Lise,

- $(\mathrm{H})$ Idun reading an e-mail from the farmer's market organization, that she receives after having contacted them with her interest to incorporate a market in her area.

\section{EVALUATING ELUNA DIGITAL GAME-BASED LEARNING FOR STEAM EDUCATION}

As mentioned earlier, during the development of the eLuna method there were six narrative digital game-based learning (DGBL) designs produced during three workshops. During the workshops there was no mention of STEM or STEAM when introducing the task of designing a digital game. Thus, an evaluation of the designs to see if they conform to STEAM has been carried out. In this section a summary of the designed narrative DGBLs is given, followed by their evaluation against the STEAM subject's science, technology, engineering, arts, and mathematics.

\section{Summary of the E-Luna Narrative Digital Game-Based Learnings}

The eLuna framework has been used to develop six narrative DGBL designs, see Table 4 for brief descriptions, through the codesign phase, and Idun's Apples, as described in detail in Section 4, through the development phase.

Table 3 presents the content of the six co-designed games according to identified agents, worlds, objects, and events.

\section{Evaluating the E-Luna Narrative Digital Game-Based Learnings Against STEAM}

To see if the seven narrative DGBLs meet support the integrated and holistic cross-disciplinary education targeted by STEAM, each design was evaluated for content related to science, technology, engineering, arts, and mathematics. As shown by Yakman (2008), there is already a conceptual trend in STEM education of purposefully integrated education related to hard sciences, with either one subject being a dominant base discipline, or where several subjects are planned to be equally represented. STEAM formally links these hard sciences to those of the Arts, creating holistic learning structures. At a multidisciplinary level, Yakman (2008) argues that the best way to teach naturally occurring interrelations, is through reality-based units. This requires disciplines from the Arts to provide context but does not necessarily need to involve all disciplines in STEM. Thus, a narrative DGBL that supports STEAM integrates one or more subjects from STEM with subjects from the Arts through naturally occurring relationships, with one or more subject being dominant. Table 5 presents the evaluation of the eLuna designs against the STEAM disciplines (the dominant base subject(s) are highlighted in bold) as defined by Yakman (2008). Some subjects, such as sustainability, belong to different disciplines based on how the subjects are covered in the designs. For example, in the mountain bike game (design number 5), sustainability is defined as the Arts, since sustainability in that design concerns attitudes and customs in society, whereas in the Idun's Apples (design number 7), sustainability is covered as a Science subject, related to what exists naturally and how it is affected. As Table 5 shows, four of the designs have main subjects related to Science and the Arts, two of the designs have main subjects related to Science, the Arts, and Mathematics, and one has a main subject related to the Arts only. All designs cover topics from all disciplines, however, none of the designs have main subjects in Technology or Engineering. The evaluation shows that the designs certainly support STEAM, and the evaluation can be used to decide in which subjects the narrative DGBL (if developed in a game) could be used to support learning.

\section{Future Work}

The narrative digital game-based learning (DGBL) investigated in this research did not consciously take STEAM into account when designed. In future eLuna research, creating new narrative DGBL, STEAM should be formally integrated, targeting STEM and Arts subjects from the beginning to explore how the framework functions when such targets are made; to see how such goals are obtainable, and to see if the support for STEAM strengthens in such cases. Furthermore, while both STEAM and narrative DGBL have been shown to have common interests in empowering stakeholders in co-design disciplines, solidifying the cross curricular subjects in the narrative DGBL, and making designs that can be specified, developed, and deployed, there is a difference in granularity between the two. In STEAM, there is emphasis on involving and empowering educators from different disciplinary backgrounds, whereas in narrative DGBL, eLuna included, the distinction is drawn between educators on one side, and developers with technical competencies on the other. In future work on the eLuna design phase, lessons should be learnt from STEAM, and, when making attempts to make consciously STEAM supporting narrative DGBL using it, eLuna, too, should distinguish between educators' areas of expertise, and strive to diversify the educator group to cover the required STEM and Arts disciplines that are to be targeted.

Inspecting the synopsis of the resulting co-designs in this research as shown in Table 4 and comparing them to 
TABLE 5 | eLuna designs support STEAM.

\begin{tabular}{|c|c|c|c|c|c|}
\hline $\begin{array}{l}\text { Candidate \# } \\
\text { and topic }\end{array}$ & Science & Technology & Engineering & Arts & Mathematics \\
\hline 1 - Deforestation & $\begin{array}{l}\text { Flora/fauna } \\
\text { Sustainability } \\
\text { Eco systems }\end{array}$ & $\begin{array}{l}\text { Barriers } \\
\text { Traps } \\
\text { Construction tools } \\
\text { Vehicles }\end{array}$ & $\begin{array}{l}\text { Construction work } \\
\text { Road blocking } \\
\text { Trap setting }\end{array}$ & $\begin{array}{l}\text { Language } \\
\text { Politics } \\
\text { Environmentalism } \\
\text { Law } \\
\text { Rhetoric }\end{array}$ & $\begin{array}{c}\text { Area measurements and } \\
\text { calculations }\end{array}$ \\
\hline 2 - Overfishing & $\begin{array}{l}\text { Fishing techniques } \\
\text { Assassination techniques }\end{array}$ & $\begin{array}{l}\text { Fishing equipment } \\
\text { Fishing boat } \\
\text { Weapons }\end{array}$ & Making fishing equipment & $\begin{array}{l}\text { Crime } \\
\text { Law } \\
\text { Social media } \\
\text { Environmentalist }\end{array}$ & $\begin{array}{l}\text { Fish population } \\
\text { measurements and } \\
\text { calculations }\end{array}$ \\
\hline 3 - Health care & $\begin{array}{l}\text { Medical diagnosis and } \\
\text { procedures }\end{array}$ & $\begin{array}{l}\text { Medical equipment used } \\
\text { to diagnose and treat }\end{array}$ & $\begin{array}{l}\text { Parameterizing or outfitting } \\
\text { medical equipment for } \\
\text { different purposes }\end{array}$ & $\begin{array}{l}\text { Health Care systems } \\
\text { Privacy } \\
\text { Social economics } \\
\text { Organizational structures }\end{array}$ & $\begin{array}{l}\text { Calculating dosages based } \\
\text { on patient physical measures }\end{array}$ \\
\hline $\begin{array}{l}4 \text { - Study } \\
\text { counselling }\end{array}$ & $\begin{array}{l}\text { Any relevant process at } \\
\text { the workplaces, e.g., in a } \\
\text { hospital, at a lab, or in a } \\
\text { university }\end{array}$ & $\begin{array}{l}\text { Any tool that can be used } \\
\text { at the workplaces, e.g., } \\
\text { medical equipment, } \\
\text { computer programs, } \\
\text { machines, and so on }\end{array}$ & $\begin{array}{c}\text { Any relevant process that } \\
\text { can be explored at the } \\
\text { workplaces, e.g., } \\
\text { construction engineering, or } \\
\text { software engineering, and } \\
\text { so on }\end{array}$ & $\begin{array}{l}\text { Career counselling and } \\
\text { path options } \\
\text { Work regulation } \\
\text { Others, as relevant to the } \\
\text { workplaces, e.g., media } \\
\text { science, social sciences, } \\
\text { and so on }\end{array}$ & $\begin{array}{l}\text { Any mathematical principle } \\
\text { applicable at the workplaces, } \\
\text { e.g., in economics, physics, } \\
\text { construction, and so on }\end{array}$ \\
\hline \multirow[t]{4}{*}{$\begin{array}{l}5 \text { - Local } \\
\text { sustainability }\end{array}$} & $\begin{array}{c}\text { Environmental } \\
\text { sciences for achieving }\end{array}$ & Bikes & Club house construction & Sustainability & $\begin{array}{l}\text { Area measurements and } \\
\text { calculations }\end{array}$ \\
\hline & minimal impact & $\begin{array}{l}\text { Building tools and } \\
\text { materials }\end{array}$ & Bike modification & Marketing & $\begin{array}{l}\text { Environmental } \\
\text { measurements and } \\
\text { calculations }\end{array}$ \\
\hline & & $\begin{array}{l}\text { Computers and/or mobile } \\
\text { phones }\end{array}$ & & Finance and investments & \\
\hline & & & & $\begin{array}{l}\text { Economics } \\
\text { Organizational structures } \\
\text { Politics }\end{array}$ & \\
\hline \multirow[t]{3}{*}{$\begin{array}{l}6 \text { - Puberty } \\
\text { biology }\end{array}$} & Biology & Mobile phones & Social engineering & Stigma & $\begin{array}{l}\text { Physical performance } \\
\text { statistics }\end{array}$ \\
\hline & Medicine & On-line platforms & & Ethics & $\begin{array}{l}\text { Social media performance } \\
\text { statistics }\end{array}$ \\
\hline & & Medical equipment & & $\begin{array}{l}\text { Law } \\
\text { Social structures } \\
\text { Media science } \\
\text { Popular culture }\end{array}$ & \\
\hline $\begin{array}{l}7 \text { - Sustainability } \\
\text { goal } 12 \text { (Idun's }\end{array}$ & Agriculture & Computers & Farming & Public regulations & $\begin{array}{l}\text { Financial balancing and } \\
\text { calculations }\end{array}$ \\
\hline \multirow[t]{4}{*}{ Apples) } & Sustainability & Irrigation systems & $\begin{array}{l}\text { Site planning and } \\
\text { construction }\end{array}$ & Organizational structures & $\begin{array}{l}\text { Environmental } \\
\text { measurements and } \\
\text { calculations }\end{array}$ \\
\hline & & $\begin{array}{l}\text { Grow houses and } \\
\text { confinements }\end{array}$ & & Finances and investments & \\
\hline & & $\begin{array}{l}\text { Measuring equipment } \\
\text { (health and sanitation } \\
\text { related) }\end{array}$ & & Business management & \\
\hline & & & & $\begin{array}{l}\text { Marketing and PR } \\
\text { Environmentalism } \\
\text { Law }\end{array}$ & \\
\hline
\end{tabular}

entertainment games found in the commercial marketplace ${ }^{12}$, shows a mismatch of topics and subjects among the two. At time of writing, six out of the top 10 bestselling PC video games ${ }^{13}$

\footnotetext{
${ }^{12}$ E.g. https://store.steampowered.com/.
}

${ }^{13} \mathrm{https} / / /$ store.steampowered.com/search/?filter=topsellers (retrieved 13th November 2021). concerns fantasy or science fiction synopsises, whereas only codesign 4 (Table 4) shows any hint of those among the eLuna narrative games discussed here. During the eLuna Framework development, one of the educators commented that $\mathrm{s} / \mathrm{he}$ though the educators had been too dominant when co-designing particularly the agents and the world of the narrative DGBL. The educator speculated that was because the educators were the authorities concerning the curriculum and the learning 
content, something that rendered the game developers' passive. This, the educator argued, was a possible short coming, given that game developers are more attuned to telling fantastic stories, stories that may just as well contain the learning material, and be more engaging to the target audience. In the next iteration, a phase to describe the setting could be introduced at the end of the eLuna preparatory phase, in which the game developers participate to create an overall setting before the co-design phase starts.

The eLuna method is built upon previous research (Breien and Wasson, 2021) that identified a particular set of categories associated with positive effects found in narrative theories for games. In future research, the eLuna framework will be refined with increased support for Variable Model categories (Breien and Wasson, 2021). For example, STEAM concepts will be included as part of the design phase, wherein the educator role will be further refined to recommend true co-design, including relevant educators from fields in STEM and the Arts, not only between educators and game developers as defined groups.

Finally, the eLuna Framework targets categories associated with positive effects, but does not ensure that these effects are obtained. Games developed on eLuna designs need to be implemented in educational settings, evaluated for their effects to inspect whether they reach their intended effects, and studied for their role in classrooms. How do teachers integrate the eLuna games into their teaching and learning activities? Do the games address the learning goals that were established in the Preparation phased? What do students learn from playing the games? After discussing such questions and evaluating effects, the eLuna Framework could fortunately become part of an iterative design and development process in which games are tuned and improved based on findings.

\section{CONCLUSION}

This article has argued that narratives are a good basis for STEAM learning and shown that the eLuna framework provides a co-design method and supporting visual language that when used by multidisciplinary co-designers results in the design of narrative digital games that can support STEAM education. We do not argue that narrative digital game-based learning (DGBL), and by extension all narratives used for learning, always and inherently supports STEAM structures, however, the designs developed in eLuna workshops resulted in narrative DGBL designs that provide high opportunity and potential for supporting STEAM education.

The co-design groups included educators, sometimes technology specialists, and game developers which enables the outcome of the co-design and co-specification processes, a blueprint, to be understood by educators and to easily be implemented by game developers. Thus, the eLuna visual language acts as a boundary object (Star and Griesemer, 1989) enabling cross-disciplinary work and meaningful collaboration between educators and game developers. The educators see the learning content presented in an organised way and the game developers can read the blueprint in a way that enables them to develop the game.

Thus, the eLuna framework empowers educators and game developers to co-design, co-specify, develop, and deploy narrative DGBL that enforce positive effects on engagement, motivation, and learning, while providing support for STEAM education in cross-curricular, integrated, and holistic learning through naturally occurring relationships. The results have been encouraging and the authors encourage the adaptation of the eLuna framework in future narrative DGBL research and development.

\section{DATA AVAILABILITY STATEMENT}

The raw data supporting the conclusions of this article will be made available by the authors, without undue reservation.

\section{ETHICS STATEMENT}

Ethical review and approval was not required for the study on human participants in accordance with the local legislation and institutional requirements. The patients/participants provided their written informed consent to participate in this study.

\section{AUTHOR CONTRIBUTIONS}

FB has contributed the ideas, the eLuna framework, and had the main responsibility for writing the text. BW has contributed to the development of the eLuna framework through supervision and has contributed both the editing and writing the text.

\section{FUNDING}

This research is part of an industrial $\mathrm{PhD}$ at the University of Bergen and Bergen Science Center (VilVite), funded by the Research Council of Norway project number 277769.

\section{ACKNOWLEDGMENTS}

The authors thank the reviewers for invaluable feedback and Nils Petter Hauan for comments and support in writing the article.

\section{SUPPLEMENTARY MATERIAL}

The Supplementary Material for this article can be found online at: https://www.frontiersin.org/articles/10.3389/feduc.2021.775746/ full\#supplementary-material 


\section{REFERENCES}

Aarseth, E. (2012). A Narrative Theory of Games. in" Proceedings of the International Conference on the Foundations of Digital Games, Raleigh, NC, May 29-June 1, 2012. Raleigh: North Carolina. doi:10.1145/ 2282338.2282365

Abelson, H., Goodman, N., and Rudolph, L. N. (1974). LOGO Manual. Cambridge, MA: Massachusetts Institute of Technology Artificial Intelligence Laboratory. https://books.google.no/books?id=Ev9zHAAACAAJ.

Arnab, S., Lim, T., Carvalho, M. B., Bellotti, F., de Freitas, S., Louchart, S., et al. (2015). Mapping Learning and Game Mechanics for Serious Games Analysis. Br. J. Educ. Technol. 46 (2), 391-411. doi:10.1111/bjet.12113

Breien, F., and Gkini, C. (2021). "The Hero's Lock Down: Differences in Learning Potential between Linear and Non-linear Narratives in Serious Games," in Games and Learning Alliance. GALA 2021. Lecture Notes in Computer Science (Cham: Springer), Vol. 13134.

Breien, F. S., and Wasson, B. (2021). Narrative Categorization in Digital Gamebased Learning: Engagement, Motivation \& Learning. Br. J. Educ. Technol., 52(1), 91-111. doi:10.1111/bjet.13004

Carvalho, M. B., Bellotti, F., Berta, R., De Gloria, A., Sedano, C. I., Hauge, J. B., et al. (2015). 2015/09/01An Activity Theory-Based Model for Serious Games Analysis and Conceptual Design. Comput. Educ. 87, 166-181. doi:10.1016/ j.compedu.2015.03.023

Curtis, G. (2008). The Cave Painters: Probing the Mysteries of the World's First Artists. New York, NY: Knopf Doubleday Publishing Group. https://books. google.no/books?id=ZoAFc2Nv9b8C.

Djaouti, D., Alvarez, J., Jessel, J.-P., and Rampnoux, O. (2011). Origins of Serious Games, 25-43. doi:10.1007/978-1-4471-2161-9_3

Finch, L., Shapiro, R. B., and Carstens, F. (2018). Teachers' Values in Co-design of an Art-Science-Computation Unit. London, UK: International Society of the Learning Sciences, Inc.

Hardin, G. (1968). The Tragedy of the Commons. Science 162 (3859), 1243-1248. doi:10.1126/science.162.3859.1243

Hemingway, E. (1995). The Old Man and the Sea. New York, NY: Scribner Paperback Fiction.

Hunter-Doniger, T., Howard, C., Harris, R., and Hall, C. (2018). STEAM through Culturally Relevant Teaching and Storytelling. Art Educ. 71 (1), 46-51. doi:10.1080/00043125.2018.1389593

Lameras, P., Arnab, S., Dunwell, I., Stewart, C., Clarke, S., and Petridis, P. (2017). Essential Features of Serious Games Design in Higher Education: Linking Learning Attributes to Game Mechanics. Br. J. Educ. Technol., 48(4), 972-994. doi:10.1111/bjet.12467

Lester, J. C., Spires, H. A., Nietfeld, J. L., Minogue, J., Mott, B. W., and Lobene, E. V. (2014). Designing Game-Based Learning Environments for Elementary Science Education: A Narrative-Centered Learning Perspective. Inf. Sci., 264, 4-18. doi:10.1016/j.ins.2013.09.005

MacDonald, A., Hunter, J., Wise, K., and Fraser, S. (2019). STEM and STEAM and the Spaces between: An Overview of Education Agendas Pertaining to 'Disciplinarity' across Three Australian StatesSTEM and STEAM and the Spaces between: An Overview of Education Agendas Pertaining to 'Disciplinarity' across Three Australian States. J-STEM 5 (1), 75-92. doi:10.51355/jstem.2019.64

Marchiori, E. J., del Blanco, Á., Torrente, J., Martinez-Ortiz, I., and FernándezManjón, B. (2011). 2011/12/01A Visual Language for the Creation of Narrative Educational Games. J. Vis. Languages Comput. 22 (6), 443-452. doi:10.1016/ j.jvlc.2011.09.001
Milara, I. S., Pitkänen, K., Laru, J., Iwata, M., Orduña, M. C., and Riekki, J. (2020). STEAM in Oulu: Scaffolding the Development of a Community of Practice for Local Educators Around STEAM and Digital Fabrication. Int. J. Child-Computer Interaction 26, 100197. doi:10.1016/ j.ijcci.2020.100197

Pant, B., Luitel, B., and Shrestha, I. M. (2020). Incorporating STEAM Pedagogy in Teaching Mathematics.

Pilegard, C., and Mayer, R. E. (2016). Improving Academic Learning from Computer-Based Narrative Games. Contemp. Educ. Psychol., 44-45, 12-20. doi:10.1016/j.cedpsych.2015.12.002

Prensky, M. (2001). Digital Natives, Digital Immigrants Part 1. On the Horizon 9, 1-6. doi:10.1145/950566.950567

Reiser, B. J. (2013). What Professional Development Strategies Are Needed for Successful Implementation of the Next Generation Science Standards. Princeton, NJ: Invitational Research Symposium on Science Assessment.

Rowe, J. P., Shores, L. R., Mott, B. W., and Lester, J. C. (2010). Individual Differences in Gameplay and Learning: a Narrative-Centered Learning Perspective. in" Proceedings of the Fifth International Conference on the Foundations of Digital Games, Monterey, CA, June 19-21, 2010. Monterey, California. doi:10.1145/1822348.1822371

Rowe, J., Shores, L., and Mott, B. (2011). Integrating Learning, Problem Solving, and Engagement in Narrative-Centered Learning Environments. J. Artif. Intelligence Educ. 21, 115-133. doi:10.3233/JAI-2011-019

Silva, F. G. M. (2020). Practical Methodology for the Design of Educational Serious Games. Information 11 (1), 14. doi:10.3390/infol1010014

Star, S. L., and Griesemer, J. R. (1989). Institutional Ecology, 'Translations' and Boundary Objects: Amateurs and Professionals in Berkeley's Museum of Vertebrate Zoology, 1907-39. Soc. Stud. Sci. 19 (3), 387-420. doi:10.1177/ 030631289019003001

Westera, W., Nadolski, R. J., Hummel, H. G. K., and Wopereis, I. G. J. H. (2008). Serious Games for Higher Education: a Framework for Reducing Design Complexity. J. Comp. Assist. Learn., 24(5), 420-432. doi:10.1111/j.13652729.2008.00279.x

Yakman, G. (2008). "STEAM Education: An Overview of Creating a Model of Integrative Education," in Pupils Attitudes Towards Technology (PATT) 2008 Annual Proceedings, Salt Lake City, UT. Editor M. de Vries, 335-358.

Zipes, J. (2012). The Irresistible Fairy Tale the Cultural and Social History of a Genre. Princeton, NJ: Princeton University Press. http://www.jstor.org/stable/j. ctt7sknm.

Conflict of Interest: The authors declare that the research was conducted in the absence of any commercial or financial relationships that could be construed as a potential conflict of interest.

Publisher's Note: All claims expressed in this article are solely those of the authors and do not necessarily represent those of their affiliated organizations, or those of the publisher, the editors and the reviewers. Any product that may be evaluated in this article, or claim that may be made by its manufacturer, is not guaranteed or endorsed by the publisher.

Copyright $\odot 2022$ Breien and Wasson. This is an open-access article distributed under the terms of the Creative Commons Attribution License (CC BY). The use, distribution or reproduction in other forums is permitted, provided the original author(s) and the copyright owner(s) are credited and that the original publication in this journal is cited, in accordance with accepted academic practice. No use, distribution or reproduction is permitted which does not comply with these terms. 